This is a self-archived version of an original article. This version may differ from the original in pagination and typographic details.

Author(s): $\begin{aligned} & \text { Juvonen, Risto O.; Ahinko, Mira; Huuskonen, Juhani; Raunio, Hannu; Pentikäinen, } \\ & \text { Olli }\end{aligned}$

Title: Development of New Coumarin-Based Profluorescent Substrates for Human

Cytochrome P450 Enzymes

Year: 2019

Version: Accepted version (Final draft)

Copyright: @ Informa Healthcare, 2019.

Rights: In Copyright

Rights url: http://rightsstatements.org/page/InC/1.0/?language=en

Please cite the original version:

Juvonen, R. O., Ahinko, M., Huuskonen, J., Raunio, H., \& Pentikäinen, O. (2019). Development of New Coumarin-Based Profluorescent Substrates for Human Cytochrome P450 Enzymes.

Xenobiotica, 49(9), 1015-1024. https://doi.org/10.1080/00498254.2018.1530399 


\title{
Development of New Coumarin-Based Profluorescent Substrates for Human Cytochrome P450 Enzymes
}

\author{
Risto O. Juvonen ${ }^{1,}$, Mira Ahinko², Juhani Huuskonen ${ }^{3}$, Hannu Raunio ${ }^{1}$, Olli T. \\ Pentikäinen $^{2,4, *}$
}

1 School of Pharmacy, Faculty of Health Sciences, University of Eastern Finland, Box 1627, 70211 Kuopio, Finland

2 University of Jyvaskyla, Department of Biological and Environmental Science \& Nanoscience Center, P.O. Box 35, FI-40014 University of Jyvaskyla, Finland

3 University of Jyvaskyla, Department of Chemistry, P.O. Box 35, FI-40014 University of Jyvaskyla, Finland

4 Institute of Biomedicine, Faculty of Medicine, Integrative Physiology and Pharmacology, University of Turku, Kiinamyllynkatu 10, FI-20520 Turku, Finland

* Corresponding authors: risto.juvonen@uef.fi (in vitro); olli.pentikainen@utu.fi (modeling and synthesis). 


\section{Abstract}

1. Cytochrome P450 (CYP) enzymes constitute an essential xenobiotic metabolizing system that regulates the elimination of lipophilic compounds from the body. Convenient and affordable assays for CYP enzymes are important for assessing these metabolic pathways.

2. In this study, 10 novel profluorescent coumarin derivatives with various substitutions at carbons 3, 6 and 7 were developed. Molecular modeling indicated that 3phenylcoumarin offers an excellent scaffold for the development of selective substrate compounds for various human CYP forms, as they could be metabolized to fluorescent 7-hydroxycoumarin derivatives. Oxidation of profluorescent coumarin derivatives to fluorescent metabolites by 13 important human liver xenobiotic-metabolizing CYP forms was determined by enzyme kinetic assays.

3. Four of the coumarin derivatives were converted to fluorescent metabolites by CYP1 family enzymes, with 6-methoxy-3-(4-trifluoromethylphenyl)coumarin being oxidized selectively by CYP1A2 in human liver microsomes. Another set of four compounds were metabolized by CYP2A6 and CYP1 enzymes. 7-Methoxy-3-(3methoxyphenyl)coumarin was oxidized efficiently by CYP2C19 and CYP2D6 in a nonselective fashion.

4. The advantages of the novel substrates were 1) an excellent signal-to-background ratio, 2) selectivity for CYP1 forms, and 3) convenient multiwell plate measurement, allowing for precise determination of potential inhibitors of important human hepatic forms CYP1A2, CYP2C19 and CYP2D6.

Keywords: drug metabolism, CYP, oxidation, fluorescence, coumarin, derivative, enzyme kinetics

\footnotetext{
Abbreviations: 3-cyano-7-ethoxycoumarin (CEC), 7-ethoxy-4-trifluoromethylcoumarin (EFC), 7-methoxy-4-trifluoromethylcoumarin (MFC), 7-methoxy-4-aminomethylcoumarin (MAMC) and 7-benzyloxy-4-trifluoromethylcoumarin (BFC)
} 


\section{INTRODUCTION}

Cytochrome P450 (CYP) monooxygenases are the most versatile enzymes that metabolize lipophilic exogenous compounds entering the body. This metabolism is an essential mechanism of elimination for both xenobiotics and harmful endogenous compounds (Gonzalez et al., 2018). The CYP enzymes comprise a very large superfamily, with 57 individual human forms identified. Of these CYP forms, approximately 10 members in the families CYP1, CYP2 and CYP3 catalyze the oxidation of xenobiotics to a significant degree (Testa et al., 2012; Guengerich 2017). CYPs are most abundantly expressed in the liver, but they are also present in other barrier tissues such as the gastrointestinal tract, lung, skin, kidney and nose epithelium (Sevior et al., 2012; Zanger and Schwab, 2013).

When new chemical compounds are developed, especially novel pharmaceuticals and pesticides, it is necessary to thoroughly evaluate their metabolic pathways and the enzymes that catalyze them. In particular, the CYP-mediated metabolism needs to be assessed. For pharmaceutical candidates, this ensures that the factors affecting their pharmacokinetics and drug interactions mediated by interference with metabolic pathways are on record (Kirchmair et al., 2015, Zientek and Youdim 2015, Fowler et al., 2017).

Inhibition of CYP enzymes is a major mechanism for metabolism-based drug interactions. Several different kinds of in vitro methods have been established to identify and quantitatively measure the type and extent of CYP inhibition. In such experiments, the CYP enzymes can be introduced into the incubation mixture as individual cDNA-expressed CYP forms or as enzyme mixtures, i.e., tissue fractions such as human liver microsomes (Pelkonen et al., 2005; 2013, Knights et al., 2016).

For the measurement of a substrate and its metabolites in in vitro assays, the most versatile analytical approaches are liquid chromatography-mass spectrometry (LC-MS) methods. The drawback of these methods is that the equipment is expensive and its use is labor intensive (Tolonen and Pelkonen, 2015). In contrast, using probe substrates that are selective for the CYP forms of interest allows the use of simple analytical methods such as fluorescence detection. High-throughput data acquisition is possible using direct profluorescent CYP substrates in a multiwell plate format. Suitable substrates for the five principal drug-metabolizing enzymes (CYP1A2, CYP2C9, CYP2C19, CYP2D6 and CYP3A4) were reported in the late 1990s (Crespi et al., 1997). Other techniques were subsequently developed, including the commercially available Vivid® fluorescent substrates (Trubetskoy et al., 2005) and 
luminogenic assays (Cali et al., 2006). These assays are based on CYP-catalyzed reactions which generate easily detectable products.

Coumarin derivatives can be converted to 7-hydroxycoumarin metabolites in an oxidation reaction typical to CYP enzymes (Figure 1). Substitution of the coumarin scaffold at the 7position with an electron-donating group yields highly fluorescent molecules (Lavis and Raines, 2014). Thus, many coumarin derivatives are used as profluorescent CYP substrates; these include 7-ethoxycoumarin, 3-cyano-7-ethoxycoumarin (CEC), 7-ethoxy-4trifluoromethylcoumarin (EFC), 7-methoxy-4-trifluoromethylcoumarin (MFC), 7-methoxy-4aminomethylcoumarin (MAMC) and 7-benzyloxy-4-trifluoromethylcoumarin (BFC). The shortcoming of these substrates is that they are not selective but are oxidized by several CYP forms (Crespi et al., 1997; Crespi and Stresser, 2000; Rendic 2000; Turpeinen et al., 2006; Waxman and Chang, 2006). Coumarin is an example of a selective substrate, as it is oxidized practically exclusively by human CYP2A6, mouse CYP2A5 and pig CYP2A19 to fluorescent 7-hydroxycoumarin (Pelkonen et al., 2000; Skaanild and Friis, 2005; Raunio and RahnastoRilla, 2012).

\section{Figure 1.}

Ideally, selective profluorescent CYP substrates would provide an efficient and low-cost toolbox for studying CYP form-specific metabolism in simple fluorescence-based assays. However, although many profluorescent substrates are available, new selective and sensitive substrates are needed as most human CYP forms are still missing the optimal profluorescent substrate. Diverse options to functionalize the coumarin core provide a wide chemical space to explore and design new CYP substrates. We have previously synthesized a series of coumarin derivatives to be evaluated as ligands for various pharmacologically important targets, including 17 $\beta$-hydroxysteroid dehydrogenases, (Niinivehmas et al., 2018) estrogen receptor $\alpha$ (Niinivehmas et al., 2016) and monoamine oxidase B (Rauhamäki et al., 2018). Some of these derivatives showed marked changes in their fluorescence properties after oxidation. This prompted us to develop novel substrates for human UDP-glucuronosyltransferase (UGT) enzymes based on the loss of fluorescence of the 7-hydroxyl-substituted coumarins upon glucuronidation (Juvonen et al., 2018). 
In this study, we expanded the coumarin-based library with 3-substituted derivatives as substrates for CYP enzymes. Novel derivatives with potentially suitable interactions with the key xenobiotic-metabolizing human CYP forms were evaluated by docking them in threedimensional CYP models. The most promising compounds were tested for their absorbance and fluorescence properties, their CYP form selectivity and their key enzyme kinetic characteristics. Several of the compounds proved to be selective, especially for CYP1A forms. Molecular modeling approaches rationalized the structural features that defined the CYP form selectivity.

\section{MATERIALS AND METHODS}

Molecular modeling. The 7-hydroxylation selectivity of the 3-phenylcoumarin derivatives by CYP forms was assessed using structural analysis, docking and multiple sequence alignment of the CYP forms. The 3D structures of the enzymes in the scope of this study were retrieved from the Protein Databank (PDB; www.rcsb.org) (Berman et al., 2000) (Supplementary Table S1), except CYP3A7, whose structure has not yet been solved. Where applicable, the selection of crystal structures was based on the bound ligands so that they would resemble the 3phenylcoumarin core as closely as possible. However, in many cases such as for CYP3A4 the bound ligands considerably diverged from this requirement. The A chains of the CYP structures were superimposed to the A chain of the CYP1A1 structure with Vertaa in Bodil and were examined visually using Bodil (Lehtonen et al., 2004). The full sequences of all the forms were acquired from the UniProt database (The UniProt Consortium, 2017) (Table S1). The multiple sequence alignment was built on top of the pre-aligned sequences derived from the above mentioned superimposition of CYP2A6 and CYP3A4 to CYP1A1, by using Malign (Wheeler and Gladstein, 1994) in Bodil with structure-based matrix (STRMAT110) (Johnson and Overington, 1993) and gap penalty of 30.

The 3D structures, protonation states, possible tautomers, conformers, and metal-binding states for the 3-phenylcoumarin derivatives at $\mathrm{pH} 7.4$ were prepared using LigPrep and ConfGenX in Schrödinger Release 2017-3 (Schrödinger LLC, New York, NY, USA, 2017). The 3phenylcoumarin analogs were docked to the CYP1A1, CYP1A2, CYP1B1, CYP2A6, CYP2D6 and CYP2C19 structures using the PANTHER protocol (Niinivehmas et al., 2015), which creates a negative image of the protein binding site, and the shape- and electrostatics-based superimposition of ShaEP (Vainio et al., 2009). Conformations that overlapped with the 
corresponding protein structure were removed. Figures were prepared using VMD 1.9.2 (Humphrey et al., 1996).

Chemicals. 7-Benzyloxy-4-trifluoromethylcoumarin (BFC) was from Corning (Corning, NY, USA). Formic acid (99\%) and $\mathrm{MgCl}_{2}$ were from Honeywell Riedel-de Haen (Bucharest, Romania). Acetonitrile (Ultra gradient HPLC grade), methanol (HPLC gradient grade) and glycine were from Fisher J.T. Baker (Waltham, Massachusetts, USA). Ethanol ( $\geq 99.5 \%$, Etax Aa) was from Altia (Helsinki, Finland). Water was deionized by MilliQ gradient A10. All chemicals were of the highest purity available from their commercial suppliers. Trichloroacetic acid, 7-hydroxy-4-trifluoromethylcoumarin (HFC), Tris-HCl, $\mathrm{MnCl}_{2}, \mathrm{MgCl}_{2}$, reduced glutathione (GSH), isocitric acid and isocitric acid dehydrogenase were purchased from SigmaAldrich (Steinheim, Germany), $\mathrm{KCl}$ from J.T. Baker, NADPH and $\mathrm{NADP}^{+}$from Roche Diagnostics (Mannheim, Germany). $200 \mathrm{~mL}$ NADPH regenerating system contained $178.5 \mathrm{mg}$ $\mathrm{NADP}^{+}$(nicotinamide adenine dinucleotide phosphate), $645 \mathrm{mg}$ isocitric acid, $340 \mathrm{mg} \mathrm{KCl}$, $240 \mathrm{mg} \mathrm{MgCl}, 0.32 \mathrm{mg} \mathrm{MnCl}_{2}$ and $15 \mathrm{U}$ isocitric acid dehydrogenase.

Synthesis of coumarin derivatives and reference compounds. Synthesis and experimental data for 1-4 and 7-10 (Figure 2) have been published earlier (Niinivehmas et al., 2018; Rauhamäki et al., 2018). Compound 6 (Figure 2) has been published by another research group (Delogu et al., 2014). BFC (11) was used a reference substrate, and the readily fluorescent 7hydroxy-3-(4-fluorophenyl)coumarin (12) was used as a surrogate standard for quantification of metabolite formation (Figure 2).

\section{Figure 2.}

A typical procedure (Figure 3.): A mixture of salicylaldehyde derivative $(2 \mathrm{mmol})$ and phenyl acetic acid derivative $(2.1 \mathrm{mmol})$, acetic acid anhydride $(0.6 \mathrm{~mL})$ and trimethylamine (TEA) $(0.36 \mathrm{~mL})$ were placed in a microwave reactor tube and this mixture was heated at $100-170^{\circ} \mathrm{C}$ with microwave apparatus for 10-20 min. After cooling, $2 \mathrm{ml}$ of $10 \% \mathrm{NaHCO}_{3}$ solution was added and the precipitate was filtered, dried and recrystallized from ethanol/ $\mathrm{H}_{2} \mathrm{O}$ or acetone $/ \mathrm{H}_{2} \mathrm{O}$ mixture. The acetyl group(s) were removed by treating the compound with methanol/ $\mathrm{NaOH}(\mathrm{aq})$ solution for $30-60 \mathrm{~min}$ at room temperature. The solution was acidified 
with $\mathrm{HCl}(\mathrm{aq})$ and the precipitate was filtered and recrystallized if needed. Based on the elemental analysis and/or 1H-NMR the purity of compounds was $>95 \%$.

\section{Figure 3.}

6-Chloro-3-(pyridin-3-yl)coumarin (5). Yield 46\%, m.p. 220-222 ${ }^{\circ}$; 1 1H-NMR(d6-DMSO, $300 \mathrm{MHz}$ ): $=7.52$ (m, 2H, H-8, H-5'), 7.69 (dd, 1H, J3 = 8.8 Hz, J4 = 2.6 Hz, H-7), 7.89 (d, 1H, J4 = 2.6 Hz, H-5), 8.12 (dd, 1H, J3 = 8.0 Hz, J4 = 2.3 Hz, J4'= 1.7 Hz, H-6), 8.33 (s, 1H, H-4), 8.63 (dd, 1H, J3 = 4.8 Hz, J4 = 1.8 Hz, H-4'), 8.88 (dd, 1H, J4 = 2.4, J5 = 0.8 Hz, H-2'); 13C-NMR(d6-DMSO): = 118.06, 120.71, 123.24, 125.38, 127.69, 128.39, 130.31, 131.61, 136.07, 140.06, 148.94, 149.61, 151.79, 159.21; Elemental analysis for $\mathrm{C}_{14} \mathrm{H}_{8} \mathrm{ClNO}_{2} \cdot 0.25 \mathrm{H}_{2} \mathrm{O}$ calc. C\% 64.14 H\% 3.27 N\% 5.34, found C\% 64.28 H\% 3.20 N\% 4.87.

6-Chloro-3-(4-hydroxyphenyl)coumarin (6). Yield 77\%, m.p. 245-247 C; 1H-NMR(d6DMSO, 300 MHz): = 6.85 (d, J3 = 7.7 Hz, H-3', H-5'), 7.45 (d, J3 = 8.8 Hz, H-8), 7.55-7.62 (m, 3H, H-7, H-2', H-6'), 7.85 (d, 1H, J4 = 2.6 Hz, H-5), 8.10 (s, 1H, H-4), 9.79 (s, 1H, Ph$\mathrm{OH})$; 13C-NMR(d6-DMSO): = 115.11, 117.74, 121.13, 124.85, 127.22, 127.81, 128.17, 129.88, 130.57, 137.11, 151.22, 158.24, 159.46; Elemental analysis for $\mathrm{C}_{15} \mathrm{H}_{9} \mathrm{ClO}_{3} \cdot 0.5 \mathrm{H}_{2} \mathrm{O}$ calc. C\% 63.96 H\% 3.58, found $\mathrm{C} \% 63.75 \mathrm{H} \% 3.42$.

Biological material. Baculovirus-insect cell-expressed human CYP1A1, CYP1A2, CYP1B1, CYP2A6, CYP2B6, CYP2C8, CYP2C9, CYP2C19, CYP2D6, CYP2E1, CYP3A4, CYP3A5 and CYP3A7 were purchased from BD Biosciences Discovery Labware (Woburn, MA, USA) and used according to the manufacturer's instructions.

The human liver tissue used in this study was obtained from the University of Oulu Hospital as surplus from organ transplantation surgery. The collection of the surplus tissue was approved by the Ethics Committee of the Medical Faculty of the University of Oulu (January 21, 1986). After surgical excision, the liver samples were immediately transferred to ice, cut into pieces, snap frozen in liquid nitrogen and stored at $-80^{\circ} \mathrm{C}$ until microsomes were prepared. Microsomes were prepared as described (Lang et al., 1981).

Spectral measurements. Absorbance spectra of the coumarin derivatives $(10 \mu \mathrm{M})$ in $100 \mathrm{mM}$ phosphate buffer $\mathrm{pH} 7.4$ were measured from $250 \mathrm{~nm}$ to $600 \mathrm{~nm}$ with a Hitachi U-2000 
spectrophotometer (Tokyo, Japan). Excitation and emission fluorescence spectra of $10 \mu \mathrm{M}$ compound 12 in $100 \mathrm{mM}$ Tris-HCL pH 7.4 were measured at $466 \mathrm{~nm}$ emission and $380 \mathrm{~nm}$ excitation, respectively, with a Shimadzu RF-5000 fluorometer (Tokyo, Japan). Compound 12 was used as a surrogate standard to quantify the formed fluorescent metabolites from nonfluorescent parent compounds.

Oxidation assays. The kinetic assays were carried out in $100 \mu \mathrm{L}$ volume containing $100 \mathrm{mM}$ Tris- $\mathrm{HCl}$ buffer $\mathrm{pH} 7.4,0-100 \mu \mathrm{M}$ coumarin derivative, 2.5-25 $\mathrm{nM}$ recombinant CYP or 0$0.1 \mathrm{~g} / \mathrm{L}$ microsomal protein and $20 \% \mathrm{NADPH}$ regenerating system. Incubations took place at $37^{\circ} \mathrm{C}$ in 96 -multiwell plates; the fluorescence was measured with a Victor ${ }^{2}$ plate reader (PerkinElmer Life Sciences, Turku, Finland). The reaction was started by adding NADPH and fluorescence measured every second minute for 40 min using excitation $405 \mathrm{~nm}$ and emission $460 \mathrm{~nm}$. Incubation without coumarin derivative, enzyme or NADPH was used as blank reaction (negative control). Compound $12(0-4 \mu \mathrm{M})$ was used as the surrogate standard to calculate the amount of product formed. The linear phase of the initial phase of the reactions was used for calculations, if it was non-linear for the whole $40 \mathrm{~min}$. In the endpoint assays the reaction was stopped at $40 \mathrm{~min}$ by adding $150 \mu \mathrm{L} 1.6 \mathrm{M}$ glycine- $\mathrm{NaOH}$ buffer $\mathrm{pH} 10.4$ and the fluorescence measured using excitation $405 \mathrm{~nm}$ and emission $460 \mathrm{~nm}$.

When the oxidation of coumarin derivatives was inhibited by $3.2 n M-20 \mu \mathrm{M} \alpha-$ naphthoflavone, the same incubation conditions and measurement setup was used. One $\mu \mathrm{L} \alpha-$ naphthoflavone was added from $100 \%$ dimethyl sulfoxide stock solution, non-inhibited sample contained $1 \%$ dimethyl sulfoxide and negative control did not contain microsomes.

\section{RESULTS}

The well-known CYP substrate coumarin, which is oxidized to fluorescent 7-hydroxycoumarin, was used as the starting point in the discovery of novel CYP form-specific substrates. Therefore, interactions between the in-house synthesized 3-phenylcoumarins and the CYP proteins were analyzed by molecular modeling to identify characteristics that support oxidation of substrate candidates to fluorescent 7-hydroxycoumarin derivatives (Figure 1).

\section{General procedure for the selection of coumarin derivatives}

Ten 3-substituted coumarin derivatives, 1-10 (Figure 2) were selected for experimental tests based on the modeling results (Figure 4) with the goal of fulfilling three criteria: 1) the molecule should fit in the catalytic site of preferably only one CYP form, 2) the compound's position 7 should either be unsubstituted or have a methoxy group and 3) position 7 should be located 
next to the heme moiety, being thus available for CYP oxidation. More detailed modeling data for the substrate selection are given below.

\section{Structural basis for the selection of coumarin derivatives}

A structural comparison of the CYP forms identified the CYP1A subfamily as the most ideal for accommodating and orienting position 7 of the 3-phenylcoumarin derivatives towards the heme for 7-hydroxylation. In the CYP1A subfamily, a hydroxyl group (Ser122 in CYP1A1 and Thr124 in CYP1A2) was available to act as a hydrogen bond donor to the coumarin carbonyl group (Figures 4A, 3B and S1). CYP1B1 is highly similar to the CYP1A forms but lacks the above-mentioned hydrogen bond donor, and therefore the 3-phenylcoumarin requires a hydrogen bond donor substituted at the 3-phenyl ring to interact with Asn265, which could orient such coumarin derivatives favorably for 7-hydroxylation (Figures 4C and S1).

\section{Figure 4.}

The coumarin core of 3-phenylcoumarins fits excellently into the substrate-binding cavity of CYP2A6 and could be stabilized into a catalyzing orientation with hydrophobic and hydrogenbonding interactions (Figure 3D: CYP2A6 with docked 6; Figure S1). To understand selective oxidation by the CYP1 forms and CYP2A6 at position 7, seven coumarin derivatives with various substitutions in positions 6 and 3-phenyl were planned for experimental testing (compounds 1-7).

Since the models of the CYP1 forms and CYP2A6 suggested that substitution at position 6 was beneficial for binding into the hydrophobic cavity of these enzymes, a compound without any substitution in position 6 was also chosen for experimental studies (8). As CYPs can catalyze O-demethylation of non-fluorescent 7-methoxycoumarin derivatives to the corresponding fluorescent 7-hydroxy derivative, compounds $\mathbf{9}$ and $\mathbf{1 0}$ were subjected to experimental testing to fully understand the binding preference of such compounds. Compound $\mathbf{1 0}$ also has a bulky substituent at the 3-phenyl ring, which tested whether flexibility of the catalytic sites allowed its entrance and whether other CYP forms with larger binding cavities, such as CYP2Cs and CYP3A4, catalyzed its oxidation to the fluorescent product.

Although the selected compounds were initially directed to the CYP1 family and CYP2A6, the experimental results showed that the compounds 9 and 10 were prominent profluorescent tool 
molecules for CYP2D6 and compounds 8 and 9 for CYP2C19 (see below). In CYP2D6, Ser304 can act as a hydrogen bond donor to orient the tested compounds for 7-hydroxylation, while the compound 10 is able to extend towards the substrate access channel (Figures 4E and S1). However, the 7-ethoxy group might be needed for the compounds to reach the reaction coordinates in CYP2D6. The 2'-ethoxy oxygen in compounds 8 and 9 can coordinate with CYP2C19 Asn107 by replacing the water molecule present in the crystal structure (Figures 4F and $\mathrm{S} 1$ ), but in the case of compound 10 this interaction is likely prevented by the additional phenyl group.

\section{Increased fluorescence after CYP mediated oxidation}

The absorbance and fluorescence properties of the selected coumarin derivatives (1-10) and the reference compounds $\mathbf{1 1}$ and $\mathbf{1 2}$ were analyzed prior to the oxidation assays. The absorbance maximums of the compounds varied between 287 and $349 \mathrm{~nm}$ (Table S2). The positive control 12 was strongly fluorescent at $460 \mathrm{~nm}$ using $405 \mathrm{~nm}$ excitation due to the 7hydroxyl substituent, whereas 1-11 lacked the 7-hydroxyl substituent and were nonfluorescent or very weakly fluorescent (Figure 5A).

Compounds 1-10 were incubated in the first experiment with pig liver microsomes and in subsequent experiments with human liver microsomes and recombinant CYPs in the presence of NADPH. The emitted fluorescence at $460 \mathrm{~nm}$ emission using excitation $405 \mathrm{~nm}$ was measured for $40 \mathrm{~min}$. For all compounds the fluorescence increased during incubation and was dependent on the amount of microsomes. However, if NADPH, the CYP enzyme or the coumarin derivative were missing (blanks), no increase in fluorescence occurred (Figure 5B). When 8 was incubated with three selected CYP forms (CYP1A1, CYP1A2, CYP2A6), the fluorescence intensity (ex $405 \mathrm{~nm}$, em $460 \mathrm{~nm}$ ) increased time-dependently (Figure 5B).

For all compounds, the signal-to-background fluorescence ratios increased steadily during the 40-min incubation (Figure 5C). The highest oxidation rates for the hydroxylation of position 7 in human liver microsomes were observed with compounds 4-6 and 9, and the lowest rates were observed with compounds 2, 3, 7 and $\mathbf{8}$ (Figure 5D). Fluorescence was higher at more alkaline $\mathrm{pH}$, such as 10.4 , than at neutral $\mathrm{pH} 7.4$, making possible the conventional endpoint measurement (data not shown). Accordingly, it could be assumed that all of the selected coumarin derivatives could act as profluorescent compounds for CYP forms.

\section{Figure 5.}




\section{Oxidation of coumarin derivatives by individual CYP forms}

A kinetic assay at a fixed substrate concentration $(10 \mu \mathrm{M})$ was used to determine the oxidation rates of all coumarin derivatives by 13 human CYP forms (Figure 6). Compounds 1-10 exhibited a greater oxidation rate than the reference compound $\mathbf{1 1}$ (BFC). The highest rates in recombinant CYPs were observed with compounds 1, 9 and 10, and the lowest rates were observed with compounds 2,5 and 8. All compounds were oxidized to some extent by CYP1A1, CYP1A2 or both. Compound $\mathbf{3}$ showed clear CYP1A selectivity, while $\mathbf{2}$ had CYP1A2 selectivity and $\mathbf{7}$ was oxidized by all three CYP1 forms. Compounds $\mathbf{4}$ and $\mathbf{5}$ were oxidized preferentially by CYP2A6. Compound 8 was oxidized by CYP2C19, CYP1A2 and CYP2A6, whereas $\mathbf{9}$ and $\mathbf{1 0}$ and the reference compound $\mathbf{1 2}$ were oxidized by multiple CYP forms.

\section{Figure 6.}

\section{Kinetic parameters}

The basic Michaelis-Menten enzyme kinetic parameters were determined for compounds 110, catalyzed by CYP1A1, CYP1A2, CYP1B1, CYP2A6, CYP2C19 and CYP2D6 (Table 1). $\mathrm{K}_{\mathrm{m}}$ values varied from $0.15 \mu \mathrm{M}$ (compound 5/CYP1A1) to $59 \mu \mathrm{M}$ (5/CYP2A6). $\mathrm{V}_{\max }$ values ranged from $0.037(8 / \mathrm{CYP} 1 \mathrm{~A} 1)$ to $35 \mathrm{~mol} /(\mathrm{min} * \mathrm{~mol} \mathrm{CYP})(\mathbf{9} / \mathrm{CYP} 1 \mathrm{~A} 2)$, and the intrinsic clearance $\left(\mathrm{V}_{\mathrm{max}} / \mathrm{K}_{\mathrm{m}}\right)$ ranged from 0.0017 (8/CYP1A1) to $49 \mathrm{~L} /(\mathrm{min} * \mathrm{~mol} \mathrm{CYP})$ (6/CYP1B1). The highest intrinsic clearance values (i.e., indicating greatest enzyme efficiency) were observed for compound 5 by CYP1A1, 9 by CYP1A2, 6 by CYP1B1 and CYP2A6, 9 by CYP2C19 and CYP2D6.

\section{Inhibition of 7-hydroxylation by $\alpha$-naphthoflavone}

The 7-hydroxylation reactions of all the new compounds were catalyzed by one or multiple CYP1 forms. Accordingly, the inhibition of the reaction in human liver microsomes by $\alpha$ naphthoflavone, a potent inhibitor of CYP1 forms, was determined (Figure 7). The 
7-hydroxylation of compound 3 was inhibited $\sim 90 \%$ at $0.1 \mu \mathrm{M} \alpha$-naphthoflavone; for the other compounds, inhibition ranged from $0 \%$ (compound 4) to $65 \%$ (compound 7).

\section{Figure 7.}

\section{DISCUSSION}

We developed 10 profluorescent coumarin derivatives, some of which showed selectivity to key human xenobiotic-metabolizing CYP forms. The excellent signal-to-background fluorescence ratio of the metabolites allowed for accurate quantification of the enzyme kinetic parameters. The novel compounds were modified differently from earlier well-known coumarin-based CYP substrates, as the substituents were either at carbon 3 or carbon 6 instead of carbon 4 or alkoxy substitution at carbon 7 . These profluorescent substrates are potentially useful for evaluating the CYP inhibition potency of nonfluorescent compounds.

After incubation in conditions supporting CYP oxidation, the change in fluorescence of all the substrates could be measured using excitation $405 \mathrm{~nm}$ and emission $460 \mathrm{~nm}$. However, the exact excitation and emission peaks differed somewhat among the compounds. The reference compound 11 (BFC) was oxidized to HFC with an emission maximum at $490 \mathrm{~nm}$. NADPH did not cause interfering fluorescence at these wavelengths, as it was excited at wavelengths $<390 \mathrm{~nm}$. There was little background fluorescence with all compounds. At lower excitation wavelengths, such as $350 \mathrm{~nm}$, the background was increased due to fluorescence of NADPH and the coumarin derivative itself.

The formation of fluorescence was monitored continuously for up to $40 \mathrm{~min}$ in the multiwell plate assay. The oxidation rate could be determined from the linear phase of the reaction. The surrogate standard $\mathbf{1 2}$ was used to calculate all oxidation rates instead of the specific 7-hydroxyl coumarin derivative formed. This was justified because both the excitation and emission peaks of the coumarin derivatives were broad and intense, and thus the maximum wavelengths did not need to be used. To obtain more precise oxidation rates the authentic 7-hydroxycoumarin derivative standards would be required, but such standards are not presently available. The reaction rate between the substrates varied by more than 100 times, as compound $\mathbf{8}$ had a $V_{\max }$ of less than $0.1 \mathrm{~mol}$ product/(min*mol CYP) catalyzed by CYP1A1, while compounds $\mathbf{1}, \mathbf{3}, \mathbf{4}$, 6, 9 and 10 showed a $V_{\max }$ of at least $10 \mathrm{~mol}$ product/(min*mol CYP) with several CYP forms. 
Similar oxidation rates have been observed previously with other coumarin-based CYP substrates such as coumarin, 6-methylcoumarin, 7-ethoxycoumarin, CEC and BFC (Crespi et al., 2002; Juvonen et al., 2016).

Simple structural comparison of the catalytic sites of the studied enzymes, combined with molecular docking, revealed that the CYP1 forms and CYP2A6, in particular, could be targeted with 3-phenylcoumarins. For the selected compounds 1-9, possible binding modes were found in one or several of the catalytic sites with the preferred orientation where the 7-position of the coumarin core or the 7-methoxy substitution was toward the heme. Experimental results showed that all 10 novel coumarins were 7-hydroxylated by at least one form in the CYP1 family. The catalytic sites of the available X-ray crystal structures of the CYP1A forms were relatively small and did not provide reasonable volume for deducing binding modes by rigid docking for the larger compound 10. Crystallization of these forms with larger substrates would be beneficial for understanding the malleability of these CYP forms.

The 3-phenylcoumarin core itself is ideal for 7-hydroxylation by the CYP1A forms. A hydrogen bond from the coumarin carbonyl to Ser122 or Thr124 in CYP1A1 or CYP1A2, respectively, can orient position 7 of the coumarin core towards the heme, while the 3-phenyl interacts with the CYP1 conserved Phe224 (CYP1A1; Figure 4A-B). CYP1B1 7-hydroxylated mainly the 3' and 4'-hydroxyl derivatives 4, 6 and 7, which could be favorably oriented in the catalytic site by forming a hydrogen bond to Asn265 (Figure 3C). Compound 3 was the most selective CYP1A substrate, being oxidized by CYP1A1 and CYP1A2 with very low rate occurring via CYP1B1. In human liver microsomes, the oxidation of $\mathbf{3}$ was completely blocked by $\alpha$-naphthoflavone, a classical inhibitor of all three CYP1 forms (Sai et al. (2000), Rendic (2002)). The CYP1A2-catalyzed $\mathrm{V}_{\max }$ of 3 ( 8 mol product/(min*mol CYP)) was clearly higher than that reported for the widely used profluorescent substrate 7-ethoxyresorufin ( 1 mol product/(min*mol CYP)) (Rendic, 2002; Ghosal et al., 2003). In addition to CYP1A1, CYP1A2 and CYP1B1, 7-ethoxyresorufin was also catalyzed weakly by CYP2B6, a relatively abundant form in human liver (Rendic, 2002). Since CYP1A1 and CYP1B1 are not constitutively expressed in human liver, (Zanger and Schwab, 2013) 3 is a potentially new selective profluorescent model substrate for CYP1A2.

Compound 2 appeared to be CYP1A2 selective with very little oxidation by the other tested hepatic CYP forms. However, $\alpha$-naphthoflavone inhibited oxidation of 2 by only $60 \%$ in human liver microsomes, suggesting that the liver contains other $\operatorname{CYP}(\mathrm{s})$ catalyzing the 
7-hydroxylation reaction. Compounds 1, 7 and 9 were oxidized by all CYP1 forms with varying contribution by other forms. Consequently, they were incompletely inhibited by $\alpha$-naphthoflavone in liver microsomes. The intrinsic clearance of $\mathbf{1}, \mathbf{3}$ and $\mathbf{7}$ by CYP1A forms was $\sim 10$ times greater than that of 2 by CYP1A2. The intrinsic clearance of 7 by CYP1B1 was the highest among these substrates.

Compounds 4, 5 and 6 were oxidized rapidly and 8 slowly by CYP2A6. These were the smallest of the selected 3-phenylcoumarins and were thus able to fit into the CYP2A6 catalytic site. Compound 7 was similar in size, but the two hydroxyl groups at positions 6 and 4' were not favored in the hydrophobic catalytic site of CYP2A6. Compounds $\mathbf{4}$ and $\mathbf{5}$ showed selectivity for CYP2A6, but the selectivity was not as clear as that of coumarin 7-hydroxylation. Accordingly, coumarin remains the most selective profluorescent substrate for CYP2A6 (Pelkonen et al., 2000; Raunio and Rahnasto-Rilla, 2012). In addition to poorer selectivity, the $K_{m}$ values of compounds 4, 5 and $\mathbf{6}$ were at least 20 times higher than that of coumarin $\left(K_{m} \sim 1\right.$ $\mu \mathrm{M}$ ) indicating that the co-substitutions at carbons 3 and 6 of the coumarin core decreased the affinity. We reported recently that the $\mathrm{K}_{\mathrm{m}}$ of 6-methylcoumarin was equal to that of coumarin and it was oxidized efficiently to a 7-hydroxyl metabolite by CYP2A6; (Juvonen et al., 2016) these results indicated that the catalytic site of CYP2A6 accepts many kinds of coumarin derivatives to be oxidized to fluorescent 7-hydroxyl metabolites.

Although the CYP1 family and CYP2A6 are both optimal enzymes for 3-phenylcoumarins in size and shape, their catalytic sites differ in shape and hydrophobicity. The catalytic site of CYP2A6 is smaller and more hydrophobic than the CYP1 catalytic sites, as CYP2A6 only has Asn297 as a hydrogen bonding residue while CYP1A has several residues that can interact with the coumarin carbonyl and the hydrogen bonding groups at the 3-phenyl ring. Accordingly, major differences in the specificity of the 7-hydroxylation of the 3phenylcoumarins between the CYP1 family and CYP2A6 are likely to result mainly from the size and hydrophobicity of the compound, with CYP2A6 being more suitable for the smallest and most hydrophobic substrates.

The oxidation of compounds 8 and 9 was catalyzed by CYP2C19, but also by other CYPs. 3-O-methylfluorescein and 7-ethoxy-3-cyanocoumarin are among the current profluorescent CYP2C19 substrates. Both compounds are also catalyzed by several other human CYP forms (Rendic (2002), Ghosal et al. (2003)). The oxidation rate of compound 9 was faster $\left(\mathrm{V}_{\max } 4.6\right.$ $\mathrm{mol} /(\mathrm{min} * \mathrm{~mol} \mathrm{CYP}))$ than the rate reported for 7-ethoxy-3-cyanocoumarin $\left(\mathrm{V}_{\max } 0.84\right.$ 
mol/(min*mol CYP)) (Ghosal et al., 2003). Compound 9 was also catalyzed by CYP2D6 with a rather high efficiency $\left(\mathrm{V}_{\max } 9.1 \mathrm{~mol} /(\mathrm{min} * \operatorname{mol} \mathrm{CYP})\right.$, and intrinsic clearance was 9.1 L/(min*mol CYP)). CYP2D6 produced fluorescent 7-hydroxyl metabolites only by O-demethylation of the 7-methoxy derivatives (compounds 9 and 10). Known profluorescent CYP2D6 substrates include 3-[2-(N,N-diethyl-N-methylammonium)-ethyl]-7-methoxy-4methylcoumarin (AMMC), MFC, MAMC and some 9-N-aminoacridine derivatives, all of which are also catalyzed by several other CYP forms (Chauret et al., 2001; Rendic, 2002; Mayer et al., 2007). However, AMMC exhibits some degree of CYP selectivity, as CYP1A1, 1A2, 1B1 and 2B6 oxidize it only weakly (Chauret et al., 2001). The reported oxidation rate of all these compounds by CYP2D6 is lower than that of $\mathbf{9}$, suggesting that $\mathbf{9}$ is potentially a new profluorescent substrate for measuring CYP2D6 activity. The lack of good selectivity is not a problem when these novel CYP2C19 and CYP2D6 substrates are used with recombinant CYP forms.

These new coumarin derivatives are not at moment commercially available. However, their synthesis is straightforward as described in the Materials and Methods section. In addition, the authors may provide compounds 1-4 and 7-10 in limited amounts upon request.

\section{CONCLUSION}

Ten coumarin derivatives were identified as profluorescent substrates for the main human liver CYP enzymes. All of these compounds were oxidized to corresponding fluorescent 7-hydroxycoumarin metabolites, and the oxidation rates by individual CYP forms and the key enzyme kinetic parameters could be determined reliably. The oxidation of all derivatives was catalyzed by the CYP1A forms with varying efficiency. Molecular modeling yielded precise information about the interactions between the compounds and individual CYP enzymes. These novel substrates would be especially suited for simple high-throughput testing of the CYP inhibition properties of nonfluorescent compounds. Our study using modeling, chemical synthesis and enzyme activity measurement of profluorescent coumarin derivatives paves the way for developing new selective or sensitive coumarin-derivative substrates for other key human CYPs. Currently we are focusing on further improving selectivity, especially towards CYP1A forms. 


\section{ACKNOWLEDGMENTS}

The project was supported by the Jenny and Antti Wihuri Foundation (MA) and the Emil Aaltonen Foundation (MA). CSC, The Finnish IT Center for Science is acknowledged for computational resources (OTP; projects jyy2516 and jyy2585).

\section{DISCLOSURE OF INTEREST}

The authors report no conflict of interest. 


\section{References}

Berman HM, Westbrook J, Feng Z, et al., (2000). The protein data bank. Nucleic Acids Res. 28: $235-242$.

Cali JJ, Ma D, Sobol M, et al., (2006). Luminogenic cytochrome P450 assays. Expert Opin. Drug Metab. Toxicol. 2: 629-645.

Chauret N, Dobbs B, Lackman RL, et al., (2001). The Use of 3- [ 2- ( N , N-Diethyl-NMethylammonium ) Ethyl ] -7-Methoxy-4- Methylcoumarin ( AMMC ) As a Specific Cyp2D6 Probe in Human Liver Microsomes. Drug Metab. Dispos. 29: 1196-1200.

Crespi CL, Miller VP, and Penman BW, (1997). Microtiter plate assays for inhibition of human, drug-metabolizing cytochromes P450. Anal. Biochem. 248: 188-190.

Crespi CL, Miller VP, and Stresser DM, (2002). Design and application of fluorometric assays for human cytochrome P450 inhibition. Methods Enzymol. 357: 276-284.

Crespi CL and Stresser DM, (2000). Fluorometric screening for metabolism-based drug-drug interactions. J. Pharmacol. Toxicol. Methods 44: 325-331.

Delogu GL, Serra S, Quezada E, et al., (2014). Monoamine oxidase (MAO) inhibitory activity: 3-phenylcoumarins versus 4-hydroxy-3-phenylcoumarins. ChemMedChem 9: 16721676.

Fowler S, Morcos PN, Cleary Y, et al., (2017). Progress in Prediction and Interpretation of Clinically Relevant Metabolic Drug-Drug Interactions: a Minireview Illustrating Recent Developments and Current Opportunities. Curr. Pharmacol. Reports 3: 36-49.

Ghosal A, Hapangama N, Yuan Y, et al., (2003). Rapid determination of enzyme activities of recombinant human cytochromes $\mathrm{P} 450$, human liver microsomes and hepatocytes. Biopharm. Drug Dispos. 24: 375-384.

Gonzalez FJ, Coughtrie M, and Tukey RH, (2018). Drug metabolism. In: L.L. Brunton, B.A. Chabner, and B.C. Knollmann, eds. Goodman \& Gilman's The Pharmacological Basis of Therapeutics. New York: McGraw-Hill, 85-100.

Guengerich FP, (2017). Intersection of the roles of cytochrome P450 enzymes with xenobiotic and endogenous substrates: Relevance to toxicity and drug interactions. Chem. Res. Toxicol. 30: 2-12. 
Humphrey W, Dalke A, and Schulten K, (1996). VMD: visual molecular dynamics. J. Mol. Graph. 14: 33-38.

Johnson MS and Overington JP, (1993). A structural basis for sequence comparisons: An evaluation of scoring methodologies. J. Mol. Biol. 233: 716-738.

Juvonen RO, Kuusisto M, Fohrgrup C, et al., (2016). Inhibitory effects and oxidation of 6methylcoumarin, 7-methylcoumarin and 7-formylcoumarin via human CYP2A6 and its mouse and pig orthologous enzymes. Xenobiotica 46: 14-24.

Juvonen RO, Rauhamäki S, Kortet S, et al., (2018). Molecular Docking-Based Design and Development of a Highly Selective Probe Substrate for UDP-glucuronosyltransferase 1A10. Mol. Pharm. 15: 923-933.

Kirchmair J, Göller AH, Lang D, et al., (2015). Predicting drug metabolism: Experiment and/or computation? Nat. Rev. Drug Discov.

Knights KM, Stresser DM, Miners JO, et al., (2016). In vitro drug metabolism using liver microsomes. Curr. Protoc. Pharmacol. 2016: 7.8.1-7.8.24.

Lang MA, Gielen JE, and Nebert DW, (1981). Genetic Evidence for Many Unique Liver Microsomal P-450-mediated Monooxygenase Activities in Heterogeneic Stock Mice. $J$. Biol. Chem. 256: 12068-12075.

Lavis LD and Raines RT, (2014). Bright building blocks for chemical biology. ACS Chem. Biol. 9: 855-866.

Lehtonen J V, Still D-J, Rantanen V-V, et al., (2004). BODIL: a molecular modeling environment for structure-function analysis and drug design. J. Comput. Aided. Mol. Des. 18: 401-19.

Mayer RT, Dolence EK, and Mayer GE, (2007). A real-time fluorescence assay for measuring N-dealkylation. Drug Metab. Dispos. 35: 103-109.

Niinivehmas S, Postila PA, Rauhamäki S, et al., (2018). Blocking oestradiol synthesis pathways with potent and selective coumarin derivatives. J. Enzyme Inhib. Med. Chem. 33: 743-754.

Niinivehmas SP, Manivannan E, Rauhamäki S, et al., (2016). Identification of estrogen receptor a ligands with virtual screening techniques. J. Mol. Graph. Model. 64: 30-39. 
Niinivehmas SP, Salokas K, Lätti S, et al., (2015). Ultrafast protein structure-based virtual screening with Panther. J. Comput. Aided. Mol. Des. 29: 989-1006.

Pelkonen O, Rautio A, Raunio H, et al., (2000). CYP2A6: A human coumarin 7-hydroxylase. Toxicology.

Pelkonen O, Turpeinen M, Hakkola J, et al., (2013). Preservation, induction or incorporation of metabolism into the in vitro cellular system - Views to current opportunities and limitations. Toxicol. Vitr. 27: 1578-1583.

Pelkonen O, Turpeinen M, Uusitalo J, et al., (2005). Prediction of drug metabolism and interactions on the basis of in vitro investigations. In: Basic and Clinical Pharmacology and Toxicology. 167-175.

Rauhamäki S, Postila PA, Niinivehmas S, et al., (2018). Structure-Activity Relationship Analysis of 3-Phenylcoumarin-Based Monoamine Oxidase B Inhibitors. Front. Chem. 6: $1-18$.

Raunio H and Rahnasto-Rilla M, (2012). CYP2A6: Genetics, structure, regulation, and function. Drug Metabol. Drug Interact. 27: 73-88.

Rendic S, (2002). Summary of information on human CYP enzymes: human P450 metabolism data. Drug Metab. Rev. 34: 83-448.

Reynald RL, Sansen S, Stout CD, et al., (2012). Structural characterization of human cytochrome P450 2C19: Active site differences between P450s 2C8, 2C9, and 2C19. J. Biol. Chem. 287: 44581-44591.

Sai Y, Dai R, Yang TJ, et al., (2000). Assessment of specificity of eight chemical inhibitors using cDNA-expressed cytochromes P450. Xenobiotica 30: 327-343.

Sevior DK, Pelkonen O, and Ahokas JT, (2012). Hepatocytes: The powerhouse of biotransformation. Int. J. Biochem. Cell Biol. 44: 257-261.

Skaanild MT and Friis C, (2005). Porcine CYP2A polymorphisms and activity. Basic Clin. Pharmacol. Toxicol. 97: 115-121.

Testa B, Pedretti A, and Vistoli G, (2012). Reactions and enzymes in the metabolism of drugs and other xenobiotics. Drug Discov. Today 17: 549-560.

The UniProt Consortium, (2017). UniProt: The universal protein knowledgebase. Nucleic 
Acids Res. 45: D158-D169.

Tolonen A and Pelkonen O, (2015). Analytical challenges for conducting rapid metabolism characterization for QIVIVE. Toxicology 332: 20-29.

Trubetskoy O V., Gibson JR, and Marks BD, (2005). Highly miniaturized formats for in vitro drug metabolism assays using Vivid?? fluorescent substrates and recombinant human cytochrome P450 enzymes. J. Biomol. Screen. 10: 56-66.

Turpeinen M, Korhonen LE, Tolonen A, et al., (2006). Cytochrome P450 (CYP) inhibition screening: comparison of three tests. Eur J Pharm Sci 29: 130-138.

Vainio MJ, Puranen JS, and Johnson MS, (2009). ShaEP : Molecular Overlay Based on Shape and Electrostatic Potential ShaEP : Molecular Overlay Based on Shape and Electrostatic Potential. Methods 49: 492-502.

Wang A, Savas U, Hsu M-H, et al., (2012). Crystal Structure of Human Cytochrome P450 2D6 with Prinomastat Bound. J. Biol. Chem. 287: 10834-10843.

Waxman DJ and Chang TKH, (2006). Use of 7-Ethoxycoumarin to Monitor Multiple Enzymes in the Human CYP1, CYP2, and CYP3 Families. In: I.R. Phillips and E.A. Shephard, eds. Cytochrome P450 Protocols. Humana Press, 153-156.

Wheeler WC and Gladstein DS, (1994). MALIGN: A multiple sequence alignment program. J. Hered. 85: 410-413.

Zanger UM and Schwab M, (2013). Cytochrome P450 enzymes in drug metabolism: Regulation of gene expression, enzyme activities, and impact of genetic variation. Pharmacol. Ther. 138: 103-141.

Zientek MA and Youdim K, (2015). Reaction phenotyping: Advances in the experimental strategies used to characterize the contribution of drug-metabolizing enzymes. Drug Metab. Dispos. 43: 163-181. 
Table 1. The Michaelis-Menten kinetic constants of the 7-hydroxylation of the coumarin derivatives catalyzed by human CYPs. Unit of $\mathrm{K}_{\mathrm{m}}$ is $\mu \mathrm{M}, \mathrm{V}_{\max } \operatorname{mol} /(\min \mathrm{x} \operatorname{mol} C Y P)$ and $\mathrm{V}_{\max } / \mathrm{K}_{\mathrm{m}} \mathrm{L} /(\min * \operatorname{mol} \mathrm{CYP})$.

\begin{tabular}{|c|c|c|c|c|c|c|c|c|}
\hline CYP1A1 & 1 & 3 & 5 & 6 & 7 & 8 & 9 & 10 \\
\hline $\mathbf{K}_{\mathrm{m}}$ & $\begin{array}{ll}5.3 & (2.7- \\
8.0) & \end{array}$ & $\begin{array}{l}2.8 \quad(1.3- \\
4.4)\end{array}$ & $\begin{array}{l}0.15 \quad(0.07- \\
0.22)\end{array}$ & $\begin{array}{l}7.7 \quad(0- \\
20.8)\end{array}$ & $1.1(0-2.8)$ & $22(0-58)$ & $\begin{array}{ll}3.3 & (1.4- \\
5.3) & \end{array}$ & $\begin{array}{l}5.5 \quad(1.9- \\
9.1)\end{array}$ \\
\hline $\mathbf{V}_{\max }$ & $\begin{array}{l}15.5(12.6- \\
18.3)\end{array}$ & $\begin{array}{l}10.1 \\
11.9)\end{array}$ & $1.1(1.0-1.3)$ & $\begin{array}{l}25.6 \quad(0- \\
58\end{array}$ & $\begin{array}{l}1.7 \quad(1.1- \\
2.2)\end{array}$ & $\begin{array}{l}0.037 \\
(0.005- \\
0.069)\end{array}$ & $\begin{array}{l}19.7(15.7- \\
23.7)\end{array}$ & $\begin{array}{l}17.6(11.9- \\
23.2)\end{array}$ \\
\hline $\mathbf{V}_{\max } / K_{m}$ & 2.9 & 3.6 & 7.3 & 3.3 & 1.5 & 0.0017 & 6.0 & 3.2 \\
\hline
\end{tabular}

\begin{tabular}{|c|c|c|c|c|c|c|c|c|}
\hline CYP1A2 & 1 & 2 & 3 & 5 & 7 & 8 & 9 & 10 \\
\hline $\mathbf{K}_{\mathbf{m}}$ & $\begin{array}{ll}1.2 & (0.8- \\
1.6) & \end{array}$ & $\begin{array}{l}10.3 \\
16.7)\end{array}$ & $\begin{array}{ll}3.2 & (2.0- \\
4.4) & \end{array}$ & $\begin{array}{l}0.4 \quad 0.29- \\
0.5)\end{array}$ & $\begin{array}{l}4.9 \\
5.5)\end{array}$ & $\begin{array}{l}0.2 \\
0.46)\end{array}$ & $\begin{array}{l}2.0 \quad(1.1- \\
2.9)\end{array}$ & $\begin{array}{l}4.0 \\
1.6)\end{array}$ \\
\hline $\mathbf{V}_{\max }$ & $\begin{array}{l}4.1 \\
4.4)\end{array}$ & $\begin{array}{l}1.21(0.87- \\
1.55)\end{array}$ & $\begin{array}{ll}7.9 & (6.9- \\
9.0) & \end{array}$ & $\begin{array}{l}0.54 \quad(0.5- \\
0.58)\end{array}$ & $\begin{array}{ll}7.1 & (6.8- \\
7.4) & \end{array}$ & $\begin{array}{l}0.22(0.19- \\
0.24)\end{array}$ & $\begin{array}{l}35.4(30.9- \\
39.9)\end{array}$ & $\begin{array}{l}11.5 \\
14.3)\end{array}$ \\
\hline $\mathbf{V}_{\max } / K_{m}$ & 3.4 & 0.12 & 2.5 & 1.35 & 1.5 & 1.1 & 17.7 & 2.9 \\
\hline
\end{tabular}

\begin{tabular}{|l|l|l|l|}
\hline CYP1B1 & $\mathbf{4}$ & $\mathbf{6}$ & $\mathbf{7}$ \\
\hline $\mathbf{K}_{\mathbf{m}}$ & $1.2(0.7-1.7)$ & $0.24(0.13-1.7)$ & $0.39(0.32-0.46)$ \\
\hline $\mathbf{V}_{\max }$ & & & \\
\hline $\mathbf{V}_{\mathbf{m a x}} / \mathbf{K}_{\mathbf{m}}$ & $2.1(1.9-2.3)$ & $11.7(10.3-13)$ & $5.0(4.8-5.1)$ \\
\hline
\end{tabular}

\begin{tabular}{|l|l|l|l|}
\hline CYP2A6 & $\mathbf{4}$ & $\mathbf{5}$ & $\mathbf{6}$ \\
\hline $\mathbf{K}_{\mathbf{m}}$ & $53(36-70)$ & $59(38-81)$ & $18.4(16.3-20.4)$ \\
\hline $\mathbf{V}_{\max }$ & $14.5(11.6-17.4)$ & $8.9(6.8-11)$ & $9.0(8.5-9.5)$ \\
\hline $\mathbf{V}_{\max } / \mathbf{K}_{\mathbf{m}}$ & 0.27 & 0.15 & 0.49 \\
\hline
\end{tabular}

\begin{tabular}{|l|l|l|}
\hline CYP2C19 & $\mathbf{8}$ & $\mathbf{9}$ \\
\hline $\mathbf{K}_{\mathbf{m}}$ & $6.5(0-13)$ & $1.9(0.9-3)$ \\
\hline $\mathbf{V}_{\max }$ & $0.39(0.2-0.57)$ & $4.6(3.8-5.4)$ \\
\hline $\mathbf{V}_{\max } / \mathbf{K}_{\mathbf{m}}$ & 0.06 & 2.4 \\
\hline
\end{tabular}

\begin{tabular}{|l|l|l|}
\hline CYP2D6 & $\mathbf{9}$ & $\mathbf{1 0}$ \\
\hline $\mathbf{K}_{\mathbf{m}}$ & $1.0(0.55-1.5)$ & $13(2.3-24)$ \\
\hline $\mathbf{V}_{\mathbf{m a x}}$ & $9.1(8.3-9.7)$ & $11.1(5-17.2)$ \\
\hline $\mathbf{V}_{\mathbf{m a x}} / \mathbf{K}_{\mathbf{m}}$ & 9.1 & 0.85 \\
\hline
\end{tabular}




\section{Figure captions}<smiles>[R]c1cc2ccc(O)cc2cc1OCC(C)(C)COc1cccc2cc([R])c(=O)oc12</smiles>

Figure 1. Change in fluorescence of coumarin derivatives upon CYP oxidation. Coumarins are oxidized to fluorescent 7-hydroxy metabolites, while hydroxylation at other positions does not increase fluorescence.
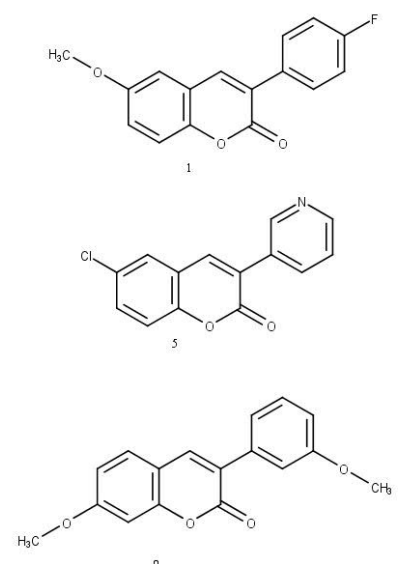
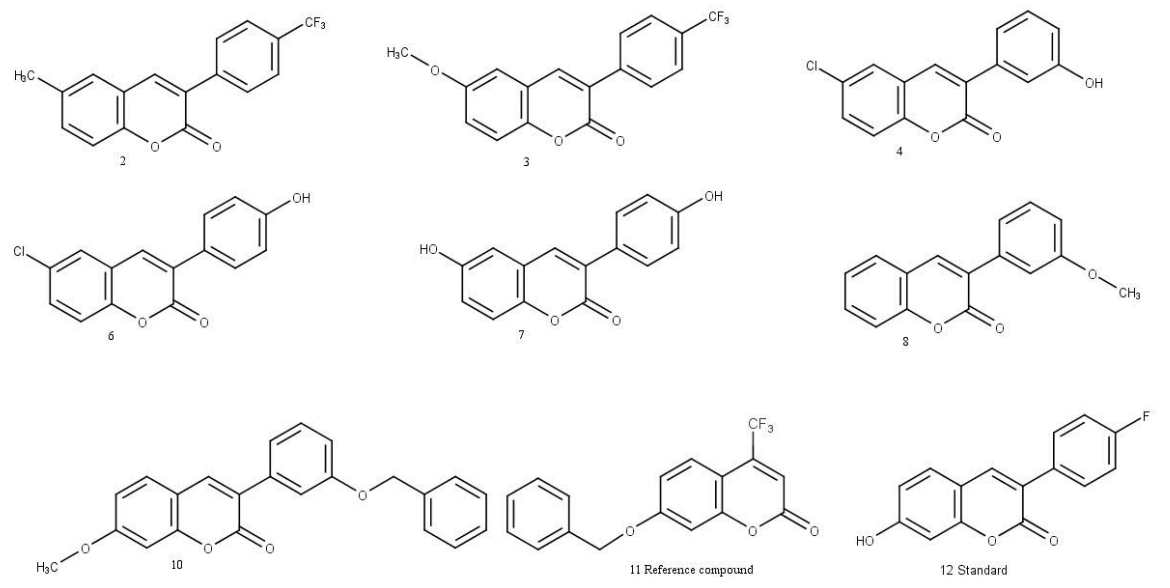

Figure 2. Structures of the studied coumarin derivatives. 1: 3-(4-fluorophenyl)-6methoxycoumarin; 2: 3-(4-trifluoromethylphenyl)-6-methylcoumarin; $\quad 3: \quad 3-(4-$ trifluoromethylphenyl)-6-methoxycoumarin; 4: 3-(3-hydroxyphenyl)-6-chlorocoumarin, 5: 3pyridyl-6-chlorocoumarin; $\quad$ 6: $\quad 3$-(4-hydroxyphenyl)-6-chlorocoumarin; $\quad$ 7: $\quad 3-(4-$ hydroxyphenyl)-6-hydroxycoumarin; 8: 3-(3-methoxyphenyl)coumarin; $\quad$ 9: 3-(3methoxyphenyl)-7-methoxycoumarin; 10: 3-(3-benzyloxo)phenyl-7-methoxycoumarin; 11: 4trifluoromethyl-7-benzyloxocoumarin; 12: 3-(4-fluorophenyl)-7-hydroxycoumarin. 
<smiles>[R]c1ccc(O)c(C(=O)[18F])c1</smiles><smiles>[R]CC(=O)O</smiles>

Figure 3. The synthesis of 3-phenylcoumarin analogs.

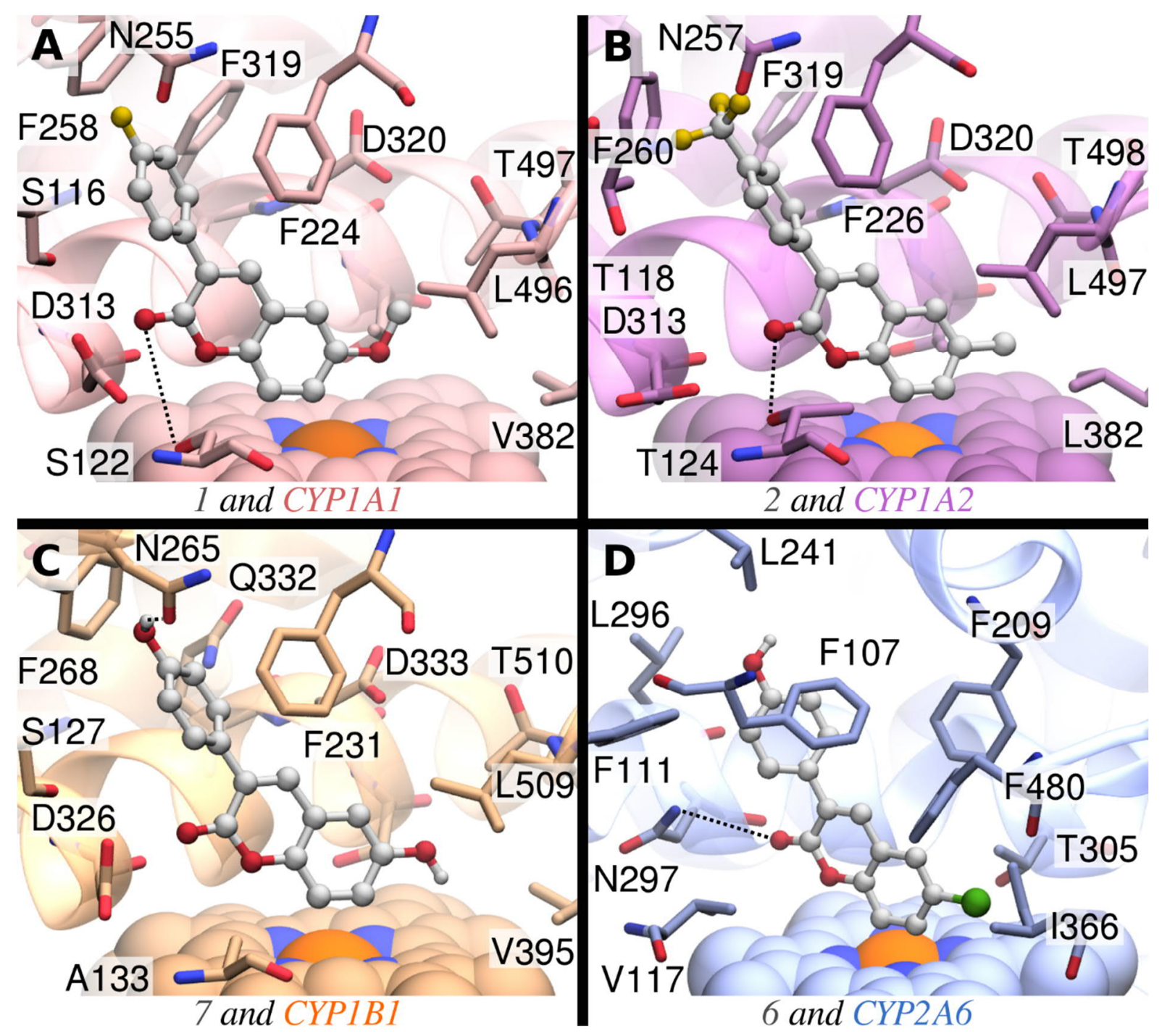

Figure 4. The binding of 3-phenylcoumarins to the CYP forms 1A1, 1A2, 1B1 and 2A6. (A) The docked pose of $\mathbf{1}$ forms a hydrogen bond from the coumarin carbonyl to the Ser122 hydroxyl group in CYP1A1 (PDB: 4I8V) (Walsh et al., 2013) and points position 7 towards the heme. (B) In CYP1A2 (PDB: 2HI4) (Sansen et al., 2007), the docked pose of compound 2 forms a hydrogen bond with Thr124 and stacks with Phe226. (C) Compound 7 forms a hydrogen bond to Asn265 and stacks with Phe231 in its docked pose to CYP1B1 (PDB: 3PM0) (Wang et al., 2011). The orientation of the 4'-hydroxy hydrogen was manipulated to show the 
hydrogen bond to Asn265. (D) The docked pose of compound 6 forms a hydrogen bond to Asn297 and packs with Phe107 in the CYP2A6 (PDB: 2FDV) (Yano et al., 2006) catalytic site. (E) Ser304 of CYP2D6 (PDB: 3QM4) (Wang et al., 2012) forms a hydrogen bond with the docked compound 10. (F) The docked compound 9 replaces the crystal water molecule (WAT) and coordinates with Asn197 in CYP2C19 (PDB: 4GQS) (Reynald et al., 2012). Ball-andstick: 3-phenylcoumarin derivatives; van der Waals: hemes; cartoon and stick: enzymes.
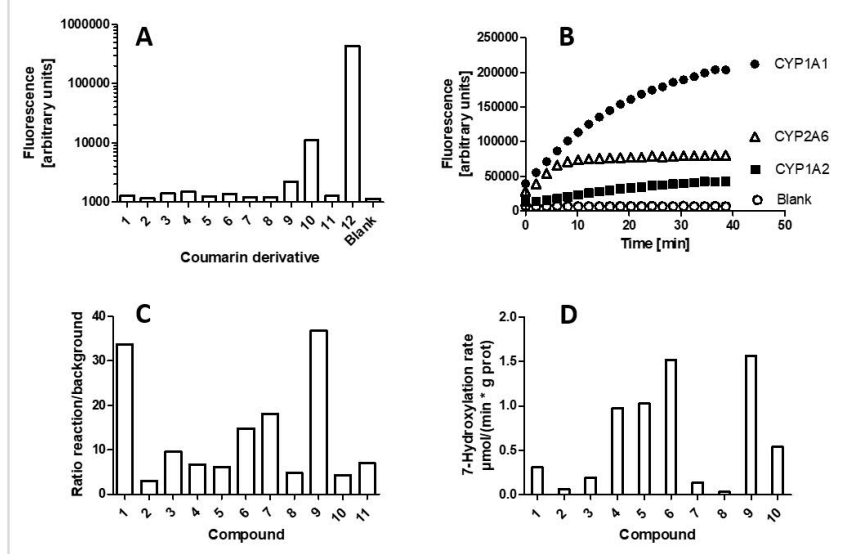

Figure 5. Fluorescence and 7-hydroxylation of the coumarin derivatives. (A) Arbitrary fluorescence intensities of all compounds $(1 \mu \mathrm{M})$ in $100 \mathrm{mM}$ Tris- $\mathrm{HCl} \mathrm{pH} 7.4$ at excitation $405 \mathrm{~nm}$ and emission $460 \mathrm{~nm}$. (B) Increase in fluorescence intensity (ex $405 \mathrm{~nm}$, em $460 \mathrm{~nm}$ ) of compound 8 during incubation with CYP1A1, CYP1A2 and CYP2A6. (C) Signal-tobackground ratio of fluorescence after $40 \mathrm{~min}$ reaction. (D) Rate of 7-hydroxylation of compounds 1-10 in human hepatic microsomes. The rate is determined from the linear phase of the reaction. The compounds $(10 \mu \mathrm{M})$ were incubated for $40 \mathrm{~min}$ in $100 \mathrm{mM}$ Tris-HCl buffer containing $0.05 \mathrm{~g} / \mathrm{L}$ microsomal protein or a $25 \mathrm{nM}$ recombinant CYP enzyme and a NADPH regenerating system. 

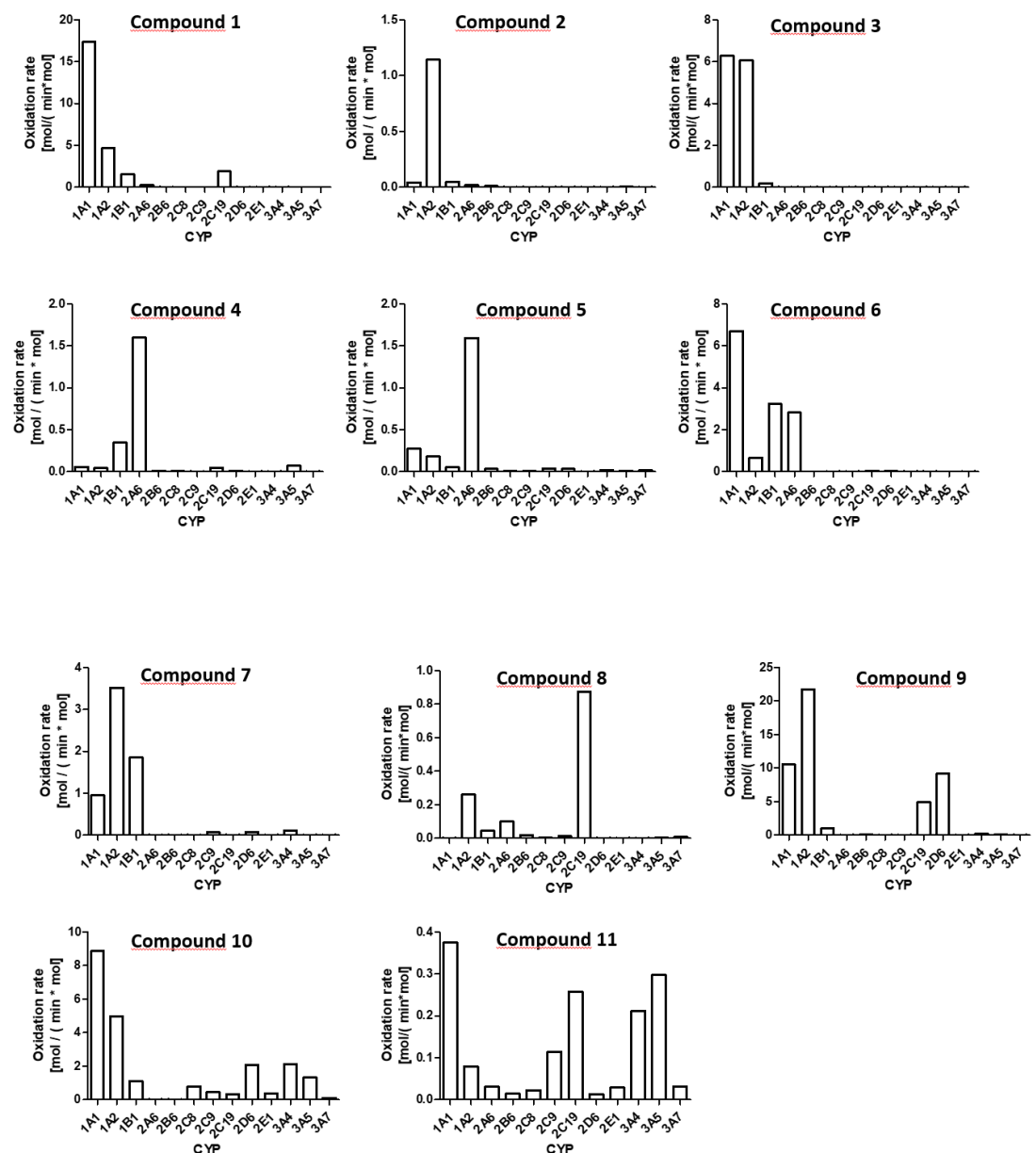

Figure 6. Oxidation of the coumarin derivatives by 13 human CYP forms. Formation of fluorescent metabolites from coumarin derivatives was determined in incubations containing a $25 \mathrm{nM}$ CYP, a 20\% NADPH regenerating system and a $10 \mu \mathrm{M}$ coumarin-derivative in $100 \mathrm{mM}$ Tris- $\mathrm{HCl} \mathrm{pH}$ 7.4. The activities were determined from the linear phases of the reactions and do not represent $\mathrm{V}_{\max }$ values. Note the variation in $\mathrm{Y}$-axis scales. 


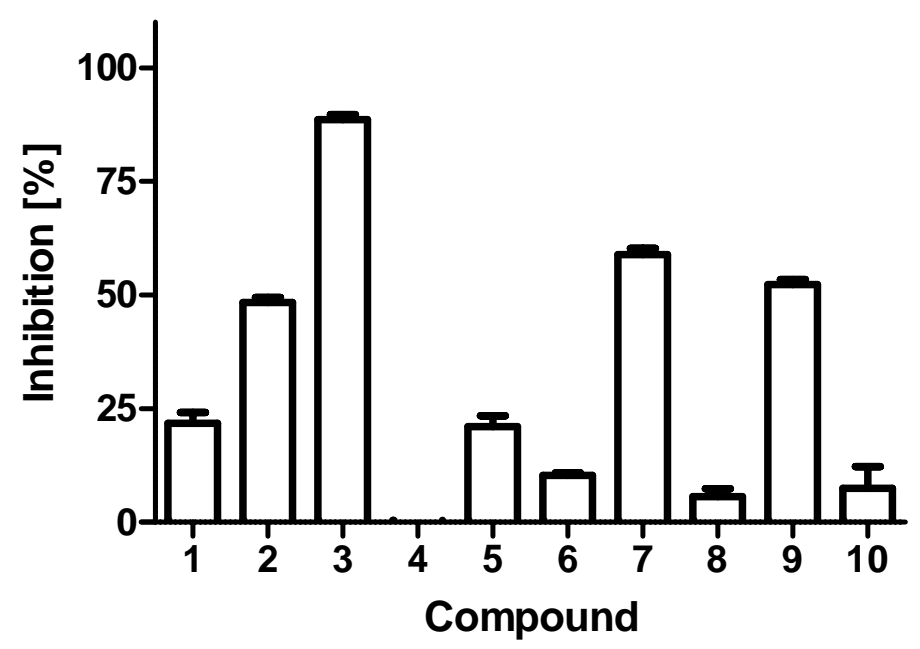

Figure 7. Inhibition of 7-hydroxylation of the coumarin derivatives by $\alpha$-naphthoflavone in human hepatic microsomes. Inhibition of fluorescent metabolite formation was determined in $100 \mathrm{mM}$ Tris-HCl pH 7.4 containing $55 \mathrm{mg} / \mathrm{L}$ microsomal protein, a NADPH regenerating system, a $10 \mu \mathrm{M}$ coumarin derivative and $0.1 \mu \mathrm{M} \alpha$-naphthoflavone. The reaction rate was determined from the linear phase of the reaction and inhibition percentage was calculated as $100 *$ inhibited rate / non-inhibited rate. Results are given as the average of two separate experiments. The error bars denote SEM. 
Supplementary Table 1. Crystal structures and amino acid sequences used in molecular modeling.

\begin{tabular}{|c|c|c|}
\hline CYP form & UniProt entry & PDB ID \\
\hline $1 \mathrm{~A} 1$ & P04798-1 & 4I8V ${ }^{\mathrm{a}, \mathrm{b}}$ (Walsh et al. 2013) \\
\hline $1 \mathrm{~A} 2$ & P05177-1 & 2HI4 ${ }^{\mathrm{a}}$ (Sansen et al. 2007) \\
\hline 1B1 & Q16678-1 & 3PM0 (Wang et al. 2011) \\
\hline \multirow[t]{2}{*}{$2 \mathrm{~A} 6$} & P11509-1 & $1 \mathrm{Z10}$ (Yano et al. 2005) \\
\hline & & 2FDV F,b $^{\mathrm{a}}$ (Yano et al. 2006) \\
\hline \multirow[t]{2}{*}{ 2B6 } & P20813-1 & 3QOA (Shah et al. 2011) \\
\hline & & 3UA5 (Shah et al. 2012) \\
\hline $2 \mathrm{C} 8$ & P10632-1 & 2VN0 (Schoch et al. 2008) \\
\hline \multirow[t]{3}{*}{$2 \mathrm{C} 9$} & P11712-1 & 1OG5 (Williams et al. 2003) \\
\hline & & 4NZ2 (Brändén et al. 2014) \\
\hline & & 1R9O (Wester et al. 2004) \\
\hline $2 \mathrm{C} 19$ & P33261-1 & 4GQS ${ }^{\mathrm{a}}$ (Reynald et al. 2012) \\
\hline \multirow[t]{2}{*}{ 2D6 } & P10635-1 & 3QM4 ${ }^{\mathrm{a}}$ (Wang et al. 2012) \\
\hline & & 4WNW (Wang et al. 2015) \\
\hline $2 \mathrm{E} 1$ & P05181-1 & 3T3Z (DeVore et al. 2012) \\
\hline \multirow[t]{2}{*}{$3 \mathrm{~A} 4$} & P08684-1 & 3UA1 (Sevrioukova \& Poulos 2012) \\
\hline & & 5TE8 ${ }^{\mathrm{b}}$ (Sevrioukova \& Poulos 2017) \\
\hline $3 \mathrm{~A} 5$ & P20815-1 & 5VEU (Hsu et al. 2018) \\
\hline $3 \mathrm{~A} 7$ & P24462-1 & - \\
\hline
\end{tabular}

a. Structures used in molecular docking

b. Structures used in structure-based sequence pre-alignment 
Supplementary Table 2 . The absorbance properties of the coumarin derivatives.

\begin{tabular}{|c|c|c|}
\hline $\begin{array}{c}\text { Compound } \\
\text { number }\end{array}$ & $\begin{array}{c}\text { Amax } \\
{[\mathrm{nm}]}\end{array}$ & $\begin{array}{c}\varepsilon \text { abs } \\
{[\mathrm{cm}-1 * \mathrm{M}-1]}\end{array}$ \\
\hline 1 & 287 & 5800 \\
\hline 2 & 293 & 6200 \\
\hline 3 & 293 & 5700 \\
\hline 4 & $\begin{array}{l}294 \\
333\end{array}$ & $\begin{array}{l}13100 \\
12300\end{array}$ \\
\hline 5 & 292 & 17900 \\
\hline 6 & 340 & 7200 \\
\hline 7 & 349 & 14900 \\
\hline 8 & 324 & 14800 \\
\hline 9 & 340 & 17400 \\
\hline 10 & 349 & 10400 \\
\hline 12 & 346 & 19300 \\
\hline
\end{tabular}


Supplementary Figure 1. Multiple sequence alignment of the CYP forms. The catalytic sites of the CYP1 family are very conserved (light pink) and have similar amino acids at the positions suggested to be involved in 3-phenylcoumarin binding (pink). CYP2A6 has a unique asparagine (teal) among the CYP2 family in addition to a well-positioned phenylalanine (teal) for possible $\pi-\pi$ interactions alongside other hydrophobic amino acids (light blue) in the eatalytic site. The catalytic site amino acids (light blue) and the suggested key residues in 3 phenylcoumarin binding (teal) differ among CYP2A6, CYP2D6 and CYP2C19. The amino acids present in either CYP3A4 or CYP3A5 binding sites (yellow) are conserved among the CYP3 forms. The conserved threonine in the helix I (black) and the heme-binding amino acids (grey) are aligned among all sequences. The alignment was built on top of structure-based prealignments of CYP2A6 and CYP3A4 to CYP1A1 from Vertaa in Bodil (Lehtonen 2004), and was performed with Malign (Johnson 1993) with structure-based matrix (STRMAT110) (Johnson \& Overington 1993) and gap penalty of 30. The structure-based pre-alignments were left out of the figure for clarity. The used structures and sequences are listed in Supplementary Table 1. 
CYP1A1

CYP1A2

CYP1B1

CYP 2A6

CYP2B 6

CYP2C19

CYP 2 C 8

CYP 2C 9

CYP 2D 6

CYP 2E

CYP $3 A 4$

CYP $3 A 5$

CYP $3 A 7$

CYP $1 A 1$

CYP1A2

CYP1B1

CYP2A 6

CYP 2B 6

CYP 2 C 19

CYP $2 \mathrm{C} 8$

CYP 2C 9

CYP 2D 6

CYP 2E 1

CYP $3 A 4$

CYP $3 A 5$

CYP $3 A 7$

CYP $1 A 1$

CYP1A2

CYP1B1

CYP2A6

CYP $2 B 6$

CYP 2C19

CYP 2C 8

CYP 2C9

CYP 2D 6

CYP2E1

CYP $3 A$

CYP $3 A 5$

CYP $3 A 7$

CYP 1A1

CYP1A2

CYP1B1

CYP 2 A 6

CYP 2B 6

CYP 2C19

CYP2C8

CYP2C

CYP 2D 6

CYP2E1

CYP $3 A 4$

CYP $3 A 5$

CYP $3 A 7$

CYP1A1

CYP1A2

CYP1B1

CYP2A

CYP 2B 6

CYP 2C19

CYP $2 \mathrm{C} 8$

CYP 2C

CYP2D 6

CYP $3 A 4$

CYP $3 A 5$

CYP $3 A 7$

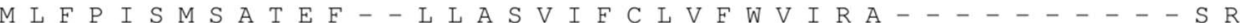

$M A L S Q S V P F S A T E L I L A S A I F C$ T V F W V L K G $M G T S L S P N D P$ W

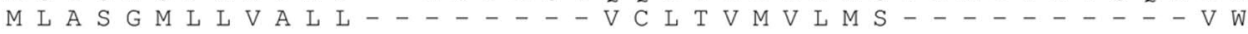
M E L S V L L F L A L L - - - - - - M D P F V V L V L C L S . . . . . . . . C L L L L S $\ldots \ldots$

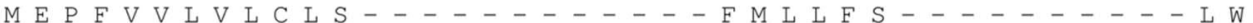
M D S L V V L V L C L S - . - . - . - C C L L L L S $\ldots \ldots$ M G L E A L V P L A V I - - - - - - V A I F L L L V D - - - - - - -

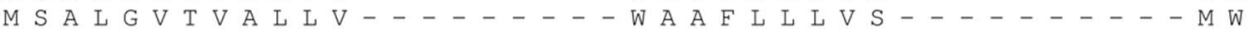
M A L I P D L A M E T W - . - . - L L L A V S L V L L Y $\ldots \ldots$

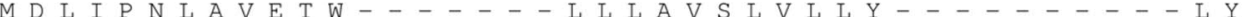

P Q V P K G L K N P - - P G P W G W P L I G H M L T L G - K N P H L A L S R M S Q $P R V P K G L K S P-\cdots P E P W G W P$ L L G H V L T L G - K N P H L A L S R M S $Q$

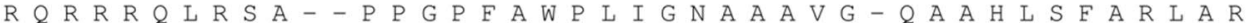
- Q ORKSKGKL - - P P G P T P L P F I G N Y L O L N T E O M Y N S L M K I S E - RH P N T H D R L - - P P G P R P L P L L G N L L Q M D R R G L L K S F I R F R E - RQS S GRGKL - - P P G P T P L P V I G N I L Q I D I K D V S K S L T N I S K - RQS C R R R L - - P P G P T P L P I I G N M L Q I D V K D I C K S F T N F S K - R Q S S G R G K L - - P P G P T P L P V I G N I L Q I G I K D I S K S I T $N$ L $S$ K $H R R Q R$ W A A P - - P P G P I P I P G L G N L L H V D F O N T P Y C F D O L R R $-R O V H S S W N L-$ P P G P F P L P I I G N L F Q L E L K N I P K S F T R I A $Q$ G T H S H G L F K K L G I P G P T P L P F L G N I L S Y H - K G F C M F D M E C H K G T R T H G L F K R L G I P G P T P L P L L G N V L S Y R - Q G L W K F D T E C

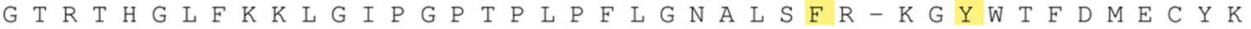

Q Y G D V L Q I R I G S T P V V V S G L D I I R Q A L V R Q G D - D F K G R P D I

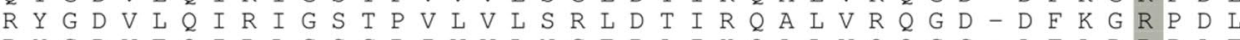

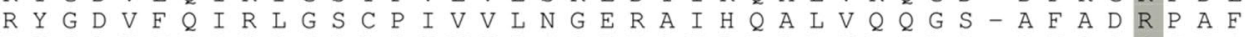
$R$ Y G P V F T I I H L G P R R V V V L C G H D A V R E A L V D Q A E KY $Y$ D V F T V H L G P R P V V M L C G V E A I R E A L V D K A E - A F S G R G K I I Y G P V F T L Y F G L E R M V V L H G Y E V V K E A L I D L G E - E F S G R G H F $V$ Y G P V F T V Y F G M N P I V V F H G Y E A V K E A L I D N G E - E F S G R G N S $V Y G P V E$ T L Y F G L K P I V V L H G Y E A V K E A L I D L G E - E F S G R G I F R F G D V F S L Q L A W T P V V V L N G L A A V R E A L V T H G E - D T A D R P P V R F G P V F T L Y V G S Q R M V V M H G Y K A V K E A L L D Y K D - E F S G R G D L $K$ Y G K V W G F Y D G $Q$ Q $P$ P V L A I T D P D M I K T V L V K E C K Y G K M W G T Y E G Q L P V L A I T D P D V I R T V L V K E C C Y S V F F T N R R S L

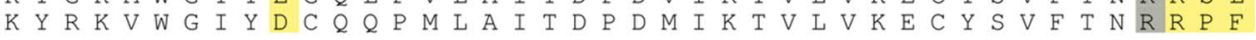

130 N107 (2C19) S122 (1A1)
150

160

Y T F I L I - - S N G O S M S S P D S G P VWA ARRR L A O N G L K S F - S I Y T S T I - . T D G Q S L T F S T D S G P VWA ARR R L A Q N A L N T F - S I A S F R V V - - - S G G R S M A F G - H Y S E H W K V O R R A A H S M M R N F F T R

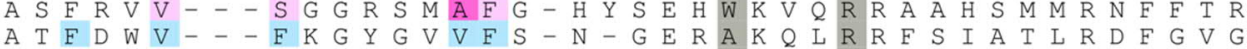

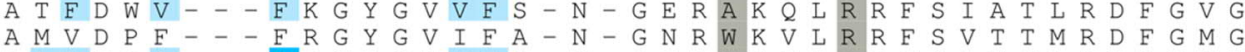

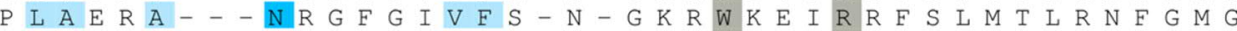
P I S Q RI - - TK G L G I S S - N-GKR WKEIRR F S L T T L R N F G M G P I A R A - - NRGFGIVFS - N - GKKWKEIRRF S I M T I R N F G M G $P$ I T O I L G F G P R S O G V F I A - R Y G P A W R E O R R F S V S T I R N I G L G

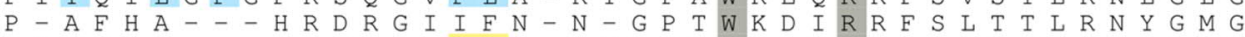
G P V G F M - - - K S A I S I A - - E D E E W K R L R S L L S P T F T S - G K I G P V G F M - - - K S A I S L A - - E D E E W K R I R S L L S P T F T S G K L G $P$ V G F M - - - KN A I S I A - E D E E W KR I R S L L S P T F T S - G K I

170

180

190

200

210

A S D P A S S T S C Y L E E H V S K E A E V L I S T L Q E L M A G P G H F N P Y R Y A S D P A S S S S C Y L E E H V S K E A K A L I S R L Q E L M A G P G H F D P Q P R S R Q - - - V L E G H V L S E A R E L V A L L V R G S A D G A F L D P R P L

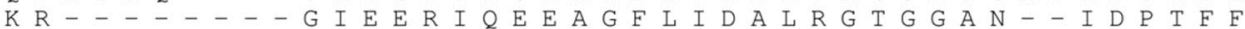

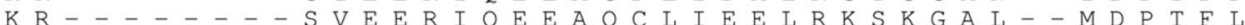
KR - - . - - - S I E D R V Q E E A R C L V E E L R K TKA S P - - C D P T F I KR - - - - - S I E D R V Q E E A H C L V E E L R K TKA S P - - C D P T F I KR - - - - - - S I E D R V Q E E A R C L V E E L R K T K A S P - - C D P T F I K K - - . - - S L E Q W V T E E A A C L C A A F A N H S G R P - - F R P N G I KQ - - - . - G N E SR I Q R E A H F L L E A L R K T Q G Q P - - F D P T F I

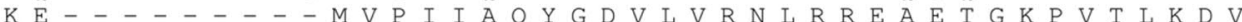
K E - - - - - - M F P I I A Q Y G D V L V R N L R R E A E K G K P V T L K D I

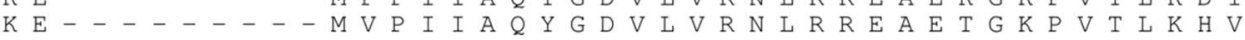


CYP1A1

CYP1A2

CYP1B1

CYP2A 6

CYP 2B 6

CYP2C19

CYP 2 C 8

CYP 2C 9

CYP 2D 6

CYP 2E 1

CYP $3 A 4$

CYP $3 A 5$

CYP $3 A 7$

CYP1A1

CYP1A2

CYP1B1

CYP2A 6

CYP2B 6

CYP 2C19

CYP2C 8

CYP2C9

CYP2D 6

CYP 2E1

CYP 3A4

CYP $3 A 5$

CYP $3 A 7$

CYP1A1

CYP 1A2

CYP1B

CYP2A6

CYP 2B 6

CYP 2C19

CYP 2C 8

CYP 2C9

CYP 2D 6

CYP2E1

CYP $3 A 4$

CYP $3 A 5$

CYP $3 A 7$

CYP1A1

CYP1A2

CYP1B1

CYP 2 A 6

CYP 2B 6

CYP 2C19

CYP2C8

CYP2C

CYP 2D 6

CYP 2E 1

CYP $3 A 4$

CYP $3 A 5$

CYP $3 A 7$

CYP1A1

CYP1A2

CYP1B1

CYP2A

CYP 2B 6

CYP 2C19

CYP 2C 8

CYP2C 9

CYP2D 6

CYP2E1

CYP $3 A 4$

CYP $3 A 5$

CYP $3 A 7$

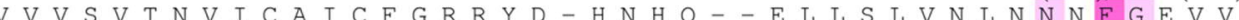
$\mathrm{V} V \mathrm{~V} S \mathrm{~V} A \mathrm{~N}$ V I G A M C F G O H F P - E S S D - - E M L S L V K N T H E F V E T A T V V A V A N V M S A C F G C R Y S - H D D P - - E F R E L L S H N E E F G R T V L S R T V S N V I S S I V F G D R F D - Y K D K - - E F L S L L R M M L G I F Q F T F Q S I T A N I I C S I V F G K R F H - Y Q D Q - - E F L K M L N L F Y Q T F $S$ L $L$ $L G C A P C N$ V I C S I I F Q K R F D - Y K D Q - C L G C A P C N V I C S V V F O KRF D - Y K D O - - N F L T L M K R F N E N F R I L L G C A P C N V I C S I I F H K R F D - Y K D Q - - Q F L N L M E K L N E $N$ I L D K A V S N V I A S L T C GR R F E - Y D D P - - R F L R L L D L A Q E G L K E E I G C A P C N V I A D I L F R K H F D - Y N D E - - K F L R L M Y L F N E N F H L L F G A Y S M D V I T S T S F G V N I D S L N N P Q D P F V E N F G A Y S M D V I T G T S F G V N I D S L N N P Q D P F V E S T K K F L K F - G F L F G A Y S M D V I T S T S F G V S I D S L N N P Q D P F V E N T K K L L R F - N P L

260

270

280 N265 (1B1)

290

GS G - N P A D F I - P I L R Y L P N P S L N A F K - - D L N E K F Y S F M Q K S S G - N P L D F F - P I LRY L P N P A L O R F K - - A F N O R F L W F L O K G A - - S V V V M - P W $Q Y F P N P V R T V F R E F E Q I N R N F S N F$ I D S T S T G O Y EMF S S V M K H L P G P O O O A F O - - - L L O G L E D F I A K S S V F G Q L F E L F S G F L K Y F P G A H R Q V Y K - - - N L Q E I N A Y I G H S I P W I Q I C N N F P T I I D Y F P G T H N K L L K - - - N L A F M E S D I L E $N S P W I Q V C N N$ P P L L I D C F P G T H N K V L K - - - N V A L T R S Y I R E $S$ S P $W$ I Q I C $N$ N F S P I I D Y F P G T H N K L L K - - - - N V A F M K S Y I L E S G F L R E V L A V P V L L H - I P A L A G K V L R - - - F O K A F L T O L D E $S T P W L Q L Y N$ N F P S F L H Y L P G S H R K V I K - - - N V A E V K E Y V S E D P F F L S I - T V F P F I I P I L E V L N I C V F P - - - - R E V T N F L R K D P L F L S I - I L F P F L T P V F E A L N V S L F P - - - - K D T I N F L S K

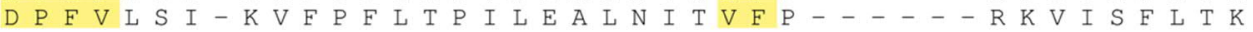

MVKEHYKTE- - EKG - - H - IRDITDSLIEHCQEKQLDENANV $T V Q E H Y Q D F--D K N-\cdots-S-V R D I T G A L F K H-S K K G P R A S G N I$ K F L R H C E S L - R P G - - A A P R D M M A F I L S A E K K A A G D S H G G KVEH N Q R T L - D P N - - S P R D F I D S F L I R M Q E E E K N P N T E $S V E K H R E T L-1 D P S-\cdots A-P K D L I D T Y L L H M E K E K S N A H S E-$ KVKEHOES M - - D I N - - N - P R D F I D C F L I K M E K E K O N O O S E KVKEHQAS L - - D V N - - N - P R D F I D C F L I K M E Q E K D N Q K S E K VKEH Q E S M - D M N - - N - P Q D F I D C F L M K M E K E K H N Q P S E L L T E H R M T W - D P A - - Q P P R D L TEA F LA E M E K A K G N P E S S R V K EHHQS L - - D P N - - C - P R D L T D C L L V E M E K E K H S A E R L $S V K R M K E S R L E D T Q-\cdots K H R V D F L Q L M I D S Q N S K E T E S H K A-$ S V N R M K K S I N D K - - - K H R I D F L Q L M I D S O N S E T E S H K A -

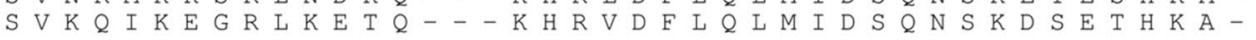

340

350 360

370

Q - - L S D E K I I N I V I D I F G G F D T V Q - I D E I IN I V I D I G A F D

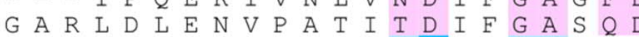
- $-F Y L K N$ L V M T T L N L F I G G T E

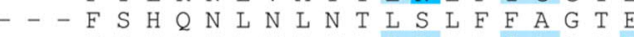
- - F T I E N L V I T A A D L L G A G T E - - Y T M D G I T V T V A D L F F A G T E - - L S D L E L V A Q S I I F I F A G Y E -

380

390

400

I I A I S W S L M Y I V M N P R V Q $V$ T A I S W S I M Y I V T K P E I Q

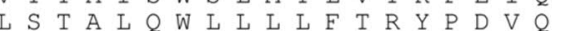
$V$ S T T T L R Y I S T T L L R Y G F L L M L K Y P H V A I S T T L R Y A L L L L L K H P E V T T S T T L R Y G L L L L L K H P E V T T S T T Y A L T I T K P E V T I S I I L A W G L L L M I L H P $P$ D $V$ T S T T T L R Y G L L I L M K Y P P E I E T S S V V L S F I M Y E E L A T T H P D V T S S V L S F T L Y E L A T H P D V Q $S S V L S F I$ I Y E L A T H P D V Q

410

420

RKI Q E E L D T V I GR SRRPR L S D R S H L P Y M E A F I L E T F R H S S F V $R K I Q K E I D T V I G R$ E R R P R L S D R P Q L P Y L E A F I I E T F R H S S F L T R V Q A E L D Q V V G R D R L P C M G D Q P N L P Y V L A F L Y E A A K V H E E I D R V I G K N R O P K F E D R A K M P Y M E A V I H E I O R F G D V I E R V Y R E I E Q V I G P H R P P E I H D R A K M P Y T E A V I Y E I C R R A K V Q E E I E R V V G R N R S P C M Q D R G H M P Y T A K V Q E E I D H V I G R H R S P C M Q D R S H M P Y T D A V V H E I Q R Y S A K V Q E E I E R V I G R N R S P C M Q D R S H M P Y T D A V V H E V Q R Y I D L L

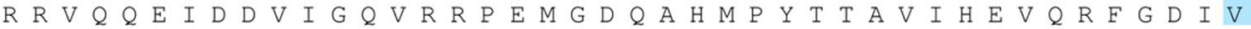
E K L H E E I D R V I G P S R I P A I K D R Q E M P Y M D A V V H E I Q $R$ O K L O E E I D A V L P N K A P P T Y D T V L O M E Y L D M V V N E T I R L F P - I $Q K$ L Q K E I D A V L P N K A P P T Y D A V V Q M E Y L D M V V N E T L R L F P - V Q K V Q K E I D T V L P N K A P P T Y D T V L Q L E Y L D M V V N E T L R L F P 
CYP $1 A 1$

CYP 1A2

CYP1B

CYP 2A

CYP 2B 6

CYP2C19

CYP2C8

CYP2C9

CYP 2D 6

CYP 2E 1

CYP $3 A 4$

CYP $3 A 5$

CYP $3 A 7$

CYP1A1

CYP1A2

CYP1B1

CYP2A 6

CYP 2 B 6

CYP 2C19

CYP2C 8

CYP 2C 9

CYP 2D 6

CYP2E1

CYP 3A4

CYP $3 A 5$

CYP $3 A 7$

CYP $1 A 1$

CYP $1 A 2$

CYP 1B1

CYP 2A 6

CYP2B 6

CYP2B 6

CYP 2C 8

CYP 2C9

CYP2D 6

CYP2E1

CYP $3 A 4$

CYP $3 A 7$

CYP1A1

CYP1A2

CYP1B1

CYP2A 6

CYP $2 B 6$

CYP 2C19

CYP 2 C 8

CYP2C

CYP 2D 6

CYP 2E 1

CYP $3 A 4$

CYP $3 A 5$

CYP 3A7

P F T I P H S T T R D T S L K G F Y I P K G R C V F V N O W O I N H D O K L W V N

$P$ F T I P

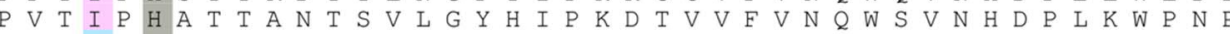
P M S L A R R V K K D T K F R D F F L P K G T E V F P M L G S V L R D P P M G V P

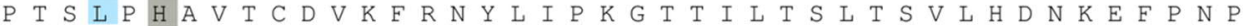
P I G V P H A V T T D T K F R N Y I I P K G T T I M A L I T S V I H D D K E F P N P T S L P H A V T C D I K F R N Y T I P K G T T L I S L T S V T H D N K E F P N P

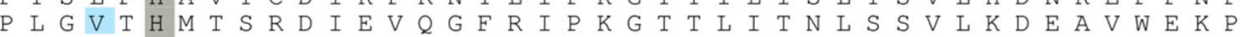

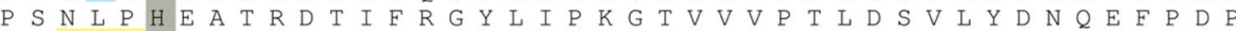
A M R L E R V C K K D V E I N G M F I P K G V V V M I P S Y A L H R A I R L E R T C K K D V E I N G V F I P K G S M V V I P T Y A

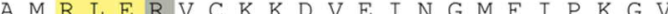

SEF L P E R F T P D G - A I D K V L S E - - KVII F G M G K R K C I G E T I A S E F R P E R F L T A D G T A I N K P L S E - - K M M L F G M G K R R C I G E V L A E N F D P A R F D K D G - I I N K D L T S - R V M I F S V G K R R C I GE E L S

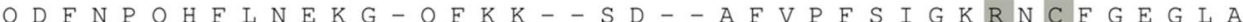
$D A F N P D H F L D A N G-A L K K--T E--A F I P F S L G K R I C I G E G I A$ EM F D P R H F L D E G G - N F K K - - S N - Y F M P F S A G K R I C V G E G L A N I F D P G H F L D K N G - N F K K - - S D - - Y F M P F S A G K R I C A G E G L A E M F D P H H F L D E G G - N F K K - - S K - - Y F M P F S A G K R I C V G E A L A FRFH P E H F D A Q G - H F V K - P E - A F L P F A G R R A C L E P L A

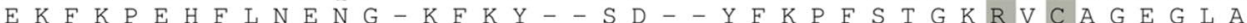
EK K F P E R F S K K N K D N I D P Y - - - I Y T P F G S G P R N C I G M R F A E E F R P E R F K K - K D S I D P Y - - - - I Y T P F G T G P R N C I G M R F A E K F L P E R F S K K N K D N I D P Y - - - - I Y T P F G S G P R N C I G M R F A

R W E V F F L A I L QRVEF SV - P L GV - KVD - - - - M T P I I G L $K W E I F L F$ L A I L L Q Q L E F S V - P P G V - K V D - - - - - L T P - I Y G L K M Q L F L F I S I L A H Q C D F R A N P N E P A K M N F S Y G I T I K R M E L F L F F T T V M N F R L S - S Q S P K D I - - - - V S P K H V G

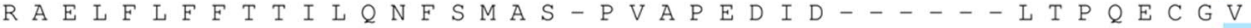

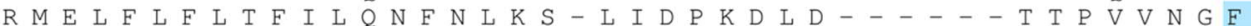
$R M E L F L F I T T I L Q N F N I K S-V D D L K N L N \ldots$ G M E L F L F L T S I L Q N F N L K S - L V D P K N L D - - - - - T T P V V N G F R M E L F L F F T S L L Q H F S F - S - V P T G Q P R P - - - - S H H G F A F R M E L F L L L C A I L Q H F N L K P - L V D P K D I D - - - - - L S P I H I G F L M N M K L A L I R V L Q N F S F K P C K E T Q I P L K - - - - - L S L G G L L $Q$ L M N M K L A L I R V L Q N F S F K P C K E T O I P L K - - - - - I D T Q G L L Q

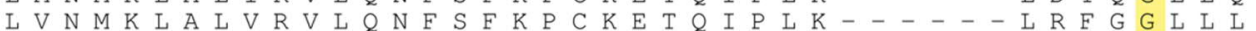

T M K H $-\mathrm{ACCEHF}-\cdots-\mathrm{Q}-\mathrm{M} \mathrm{Q}$ L R S - T M K - ARCEHV - - - Q - ARRESTNN V T L R E S M E L L D S A V Q N L Q A A K E T C C A T I P - R N Y T M S - - - F L P R - GKI P - P T Y Q I R - . - - F L P R - - A S V P - P F Y O L C $\ldots \ldots$. - F I P V $\ldots \ldots$ V S L P - P S Y Q I C - - - - F I P V - - A S V P - P F Y Q I C - - - - F I P V - - R S - - P E K P V V L K V E S - - R D G T V S G A - - P E K P I V L K V D S - - R D G T L S G E - - - 


\section{References}

Brändén, G. et al., (2014). Structure-based ligand design to overcome CYP inhibition in drug discovery projects. Drug Discovery Today, 19: 905-911.

DeVore, N.M. et al., (2012). Structural comparison of cytochromes P450 2A6, 2A13, and 2E1 with pilocarpine. FEBS Journal, 279: 1621-1631.

Hsu, M.-H., Savas, U. \& Johnson, E.F., (2018). The X-Ray Crystal Structure of the Human Mono-Oxygenase Cytochrome P450 3A5-Ritonavir Complex Reveals Active Site Differences between P450s 3A4 and 3A5. Molecular Pharmacology, 93: 14-24. Available at: http://molpharm.aspetjournals.org/lookup/doi/10.1124/mol.117.109744.

Johnson, M.S. \& Overington, J.P., (1993). A structural basis for sequence comparisons: An evaluation of scoring methodologies. Journal of Molecular Biology, 233: 716-738.

Reynald, R.L. et al., (2012). Structural characterization of human cytochrome P450 2C19: Active site differences between P450s 2C8, 2C9, and 2C19. Journal of Biological Chemistry, 287: 44581-44591.

Sansen, S. et al., (2007). Adaptations for the oxidation of polycyclic aromatic hydrocarbons exhibited by the structure of human P450 1A2. Journal of Biological Chemistry, 282: $14348-14355$.

Schoch, G.A. et al., (2008). Determinants of cytochrome P450 2 C8 substrate binding: Structures of complexes with montelukast, troglitazone, felodipine, and 9-cis-retinoic acid. Journal of Biological Chemistry, 283: 17227-17237.

Sevrioukova, I.F. \& Poulos, T.L., (2012). Structural and mechanistic insights into the interaction of cytochrome P4503A4 with bromoergocryptine, a type I ligand. Journal of Biological Chemistry, 287: 3510-3517.

Sevrioukova, I.F. \& Poulos, T.L., (2017). Structural basis for regiospecific midazolam oxidation by human cytochrome P450 3A4. Proceedings of the National Academy of Sciences, 114: 486-491. Available at: http://www.pnas.org/lookup/doi/10.1073/pnas.1616198114.

Shah, M.B. et al., (2012). Conformational adaptation of human cytochrome P450 2B6 and rabbit cytochrome P450 2B4 revealed upon binding multiple amlodipine molecules. Biochemistry, 51: 7225-7238. 
Shah, M.B. et al., (2011). Structures of cytochrome P450 2B6 bound to 4-benzylpyridine and. Molecular pharmacology, 80: 1047-1055.

Walsh, A.A., Szklarz, G.D. \& Scott, E.E., (2013). Human cytochrome P450 1A1 structure and utility in understanding drug and xenobiotic metabolism. Journal of Biological Chemistry, 288: 12932-12943.

Wang, A. et al., (2015). Contributions of ionic interactions and protein dynamics to cytochrome P450 2D6 (CYP2D6) substrate and inhibitor binding. Journal of Biological Chemistry, 290: 5092-5104.

Wang, A. et al., (2012). Crystal Structure of Human Cytochrome P450 2D6 with Prinomastat Bound. Journal of Biological Chemistry, 287: 10834-10843. Available at: http://www.jbc.org/lookup/doi/10.1074/jbc.M111.307918.

Wang, A. et al., (2011). Structural characterization of the complex between ??-naphthoflavone and human cytochrome P450 1B1. Journal of Biological Chemistry, 286: 5736-5743.

Wester, M.R. et al., (2004). The structure of human cytochrome P450 2 C9 complexed with flurbiprofen at 2.0-Å resolution. Journal of Biological Chemistry, 279: 35630-35637.

Williams, P. a et al., (2003). Crystal structure of human cytochrome P450 2C9 with bound warfarin. $\quad$ Nature, 424: 464-468. Available at: http://www.nature.com/nature/journal/v424/n6947/abs/nature01862.html.

Yano, J.K. et al., (2005). Structures of human microsomal cytochrome P450 2A6 complexed with coumarin and methoxsalen. Nature Structural and Molecular Biology, 12: 822-823.

Yano, J.K. et al., (2006). Synthetic inhibitors of cytochrome P-450 2A6: Inhibitory activity, difference spectra, mechanism of inhibition, and protein cocrystallization. Journal of Medicinal Chemistry, 49: 6987-7001. 